\title{
Timing of Introduction of Complementary Foods and Beverages and Food Allergy, Atopic Dermatitis/Eczema, Asthma, and Allergic Rhinitis: A Systematic Review
}

The Pregnancy and Birth to 24 Months Project

Published date: April 15, 2019

Nutrition Evidence Systematic Review Center for Nutrition Policy and Promotion

Food and Nutrition Service U.S. Department of Agriculture

3101 Park Center Drive Alexandria, Virginia 
This systematic review was conducted for the Pregnancy and Birth to 24 Months Project (P/B-24 Project) by the Nutrition Evidence Systematic Review (NESR) team at the Center for Nutrition Policy and Promotion, Food and Nutrition Service, USDA. All systematic reviews from the P/B-24 Project are available on the NESR website: https://nesr.usda.gov.

Conclusion statements drawn as part of this systematic review describe the state of science related to the specific question examined. Conclusion statements do not draw implications, and should not be interpreted as dietary guidance.

The contents of this document may be used and reprinted without permission. Endorsements by NESR, the Center for Nutrition Policy and Promotion, the Food and Nutrition Service, or the U.S. Department of Agriculture (USDA) of derivative products developed from this work may not be stated or implied.

In accordance with Federal civil rights law and USDA civil rights regulations and policies, the USDA, its Agencies, offices, and employees, and institutions participating in or administering USDA programs are prohibited from discriminating based on race, color, national origin, religion, sex, gender identity (including gender expression), sexual orientation, disability, age, marital status, family/parental status, income derived from a public assistance program, political beliefs, or reprisal or retaliation for prior civil rights activity, in any program or activity conducted or funded by USDA (not all bases apply to all programs). Remedies and complaint filing deadlines vary by program or incident.

Persons with disabilities who require alternative means of communication for program information (e.g., Braille, large print, audiotape, American Sign Language, etc.) should contact the responsible Agency or USDA's TARGET Center at (202) 720-2600 (voice and TTY) or contact USDA through the Federal Relay Service at (800) 877-8339. Additionally, program information may be made available in languages other than English.

To file a program discrimination complaint, complete the USDA Program Discrimination Complaint Form, AD3027, found online at How to File a Program Discrimination Complaint and at any USDA office or write a letter addressed to USDA and provide in the letter all of the information requested in the form. To request a copy of the complaint form, call (866) 632-9992. Submit your completed form or letter to USDA by: (1) mail: U.S. Department of Agriculture, Office of the Assistant Secretary for Civil Rights, 1400 Independence Avenue, SW, Washington, D.C. 20250-9410; (2) fax: (202) 690-7442; or (3) email: program.intake@usda.gov.

USDA is an equal opportunity provider, employer, and lender.

Suggested citation for this systematic review: Nutrition Evidence Systematic Review Team and Complementary Feeding Technical Expert Collaborative. Timing of Introduction of Complementary Foods and Beverages and Food Allergy, Atopic Dermatitis/Eczema, Asthma, and Allergic Rhinitis: A Systematic Review. Pregnancy and Birth to 24 Months Project. Alexandria, VA: U.S. Department of Agriculture, Food and Nutrition Service, Center for Nutrition Policy and Promotion, February 2019. Available at: https://nesr.usda.gov/projectspecific-overview-pb-24-0

This systematic review has also been published in the American Journal of Clinical Nutrition: Obbagy JE, English LK, Wong YP, Butte NF, Dewey KG, Fleischer DM, et al. Complementary feeding and food allergies, atopic dermatitis and eczema, asthma, and allergic rhinitis: a systematic review. Am J Clin Nutr. 2019;109(7):890S-934S. doi: 10.1093/ajcn/nqy220.

Related citations are published in the American Journal of Clinical Nutrition:

- $\quad$ P/B-24 Project overview: Stoody EE, Spahn JM, Casavale KO. The Pregnancy and Birth to 24 Months Project: a series of systematic reviews on diet and health. Am J Clin Nutr. 2019;109(7):685S97S. doi: 10.1093/ajcn/nqy372.

- P/B-24 systematic review methodology: Obbagy JE, Spahn JM, Wong YP, Psota TL, Spill MK, Dreibelbis C, et al. Systematic review methodology used in the Pregnancy and Birth to 24 Months Project. Am J Clin Nutr. 2019;109(7):698S-704S. doi: 10.1093/ajcn/nqy226.

- Related systematic reviews from the P/B-24 Project:

o English LK, Obbagy JE, Wong YP, Butte NF, Dewey KG, Fox MK, et al. Timing of introduction 
of complementary foods and beverages and growth, size, and body composition: a systematic review. Am J Clin Nutr. 2019;109(7):935S-55S. doi: 10.1093/ajcn/nqy267.

o English LK, Obbagy JE, Wong YP, Butte NF, Dewey KG, Fox MK, et al. Types and amounts of complementary foods and beverages consumed and growth, size, and body composition: a systematic review. Am J Clin Nutr. 2019;109(7):956S-77S. doi: 10.1093/ajcn/nqy281.

o English LK, Obbagy JE, Wong YP, Butte NF, Dewey KG, Fox MK, et al. Complementary feeding and developmental milestones: a systematic review. Am J Clin Nutr.

2019;109(7):879S-89S. doi: 10.1093/ajcn/nqy321.

o Obbagy JE, English LK, Psota TL, Wong YP, Butte NF, Dewey KG, et al. Complementary feeding and micronutrient status: a systematic review. Am J Clin Nutr. 2019;109(7):852S71S. doi: 10.1093/ajen/nqy266.

o Obbagy JE, English LK, Wong YP, Butte NF, Dewey KG, Fox MK, et al. Complementary feeding and bone health: a systematic review. Am J Clin Nutr. 2019:872S-8S. doi: 10.1093/ajcn/nqy227. 


\section{ACKNOWLEDGEMENTS}

\section{Complementary Feeding Technical Expert Collaborative (TEC):}

- Nancy F. Butte, PhD, RD, United States Department of Agriculture /Agricultural Research Service, Children's Nutrition Research Center, Baylor College of Medicine, Department of Pediatrics, Emeritus

- Kathryn G. Dewey, PhD, University of California, Davis, Department of Nutrition

- David M. Fleischer, MD, Children's Hospital Colorado, University of Colorado School of Medicine, Department of Pediatrics, Section of Allergy and Immunology

- Mary Kay Fox, Med, Mathematica Policy Research

- Frank R. Greer, MD, University of Wisconsin School of Medicine and Public Health, Department of Pediatrics, Emeritus

- Nancy F. Krebs, MD, MS, University of Colorado School of Medicine, Department of Pediatrics

- Kelley S. Scanlon, PhD, RD, United States Department of Agriculture, Food and Nutrition Service (formerly of the Centers for Disease Control and Prevention, Division of Nutrition, Physical Activity, and Obesity)

\section{Nutrition Evidence Systematic Review (NESR) team:}

- Julie E. Obbagy, PhD, RD USDA, Lead Analyst (05/2016-project completion)

- Laural K. Englishi, PhD, Panum Group, Analyst (11/2016-project completion)

- Tricia L. Psota, USDA, Lead Analyst (07/2015-06/2016)

- Perrine Nadaudi, MS, Panum Group, Analyst (07/2015-05/2016)

- Kirsten Johnsi, MS, USDA, Panum Group, Analyst (07/2015-05/2016)

- Yat Ping Wong, MLS, MPH, USDA, Librarian

- Nancy Terry, MLS, NIH, Librarian

\section{Project Lead:}

- Eve Essery Stoody, PhD, USDA

\section{Federal Expert Group (FEG)-Technical Expert Collaborative (TEC) Liaisons:}

- Kelley S. Scanlon, PhD, RD, United States Department of Agriculture, Food and Nutrition Service (formerly of the Centers for Disease Control and Prevention, Division of Nutrition, Physical Activity, and Obesity)

All TEC and NESR team members, Project leads, and FEG-TEC liaisons participated in establishing the research questions, analytic framework, and study inclusion and exclusion criteria. JEO, LKE, TLP, PN, KJ, YWP, and NT developed and conducted the literature search, screened search results, and identified studies for inclusion. JEO and LKE extracted data and assessed risk of bias for included studies. NFC, KGD, MKF, FRG, NFK, DF and KSS reviewed and provided substantive feedback on all systematic review materials, including the synthesis of the body of evidence, conclusion statement,

i Under contract with the Food and Nutrition Service, United States Department of Agriculture. 
and grade of the strength of the evidence. JEO prepared this report and EES provided oversight. All authors critically reviewed and approved the final report. The authors declare no conflicts of interest.

FUNDING SOURCE: United States Department of Agriculture, Food and Nutrition Service, Center for Nutrition Policy and Promotion, Alexandria, VA 


\section{TABLE OF CONTENTS}

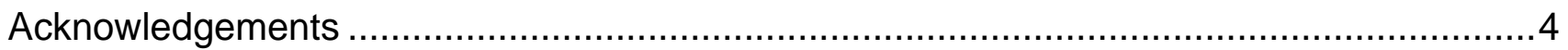

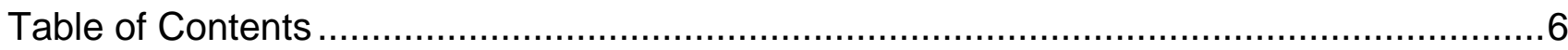

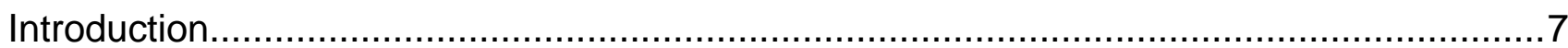

What is the relationship between timing of introduction of complementary foods and beverages (CFB) and food allergy, atopic dermatitis/eczema, asthma, and allergic rhinitis? 9

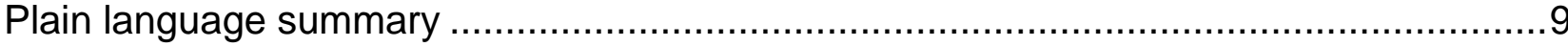

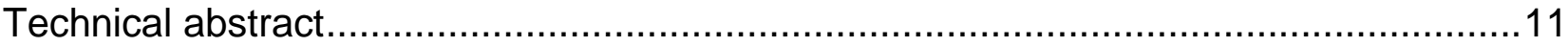

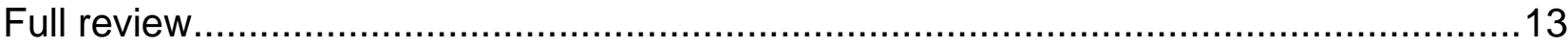

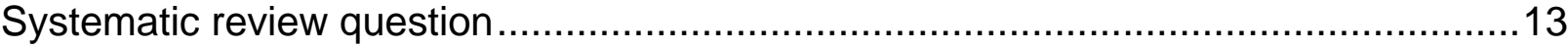

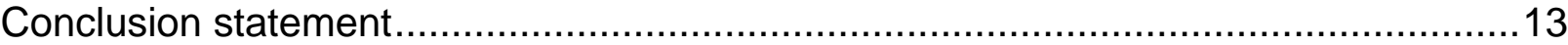

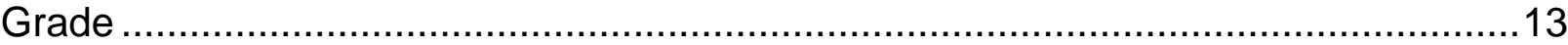

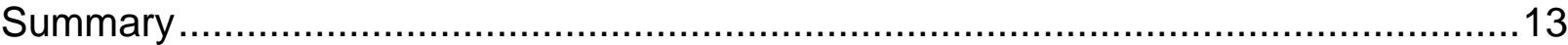

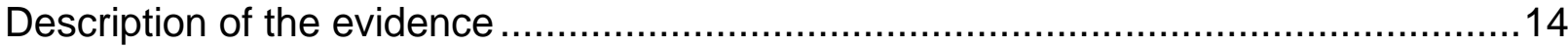

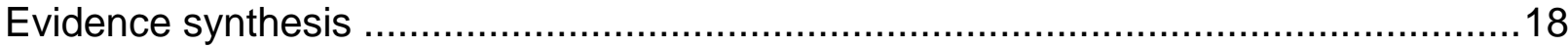

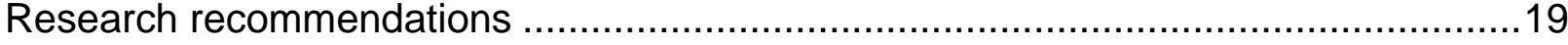

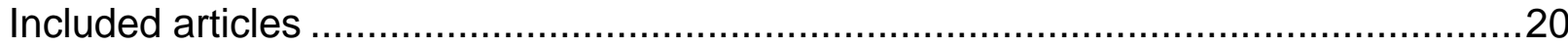

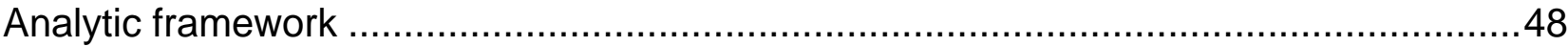

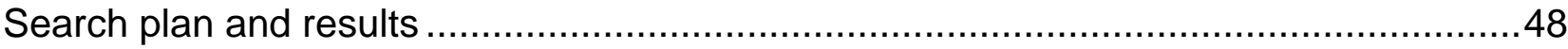

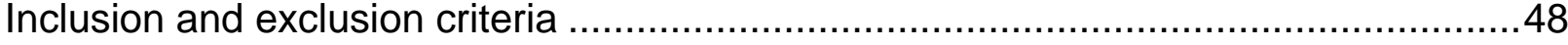

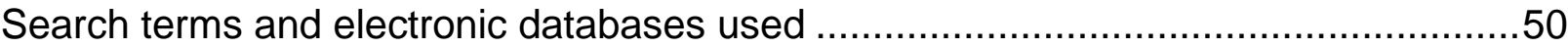

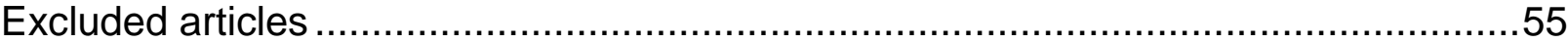

Table 1. Description of studies examining the relationship between the timing of introduction of complementary foods and beverages (CFB) and food allergy, atopic dermatitis/eczema,

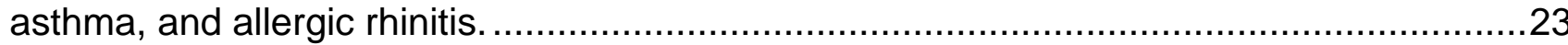
Table 2. Results from studies that examined the relationship between age of first introduction of any complementary foods and/or beverages (CFB) and food allergy, atopic

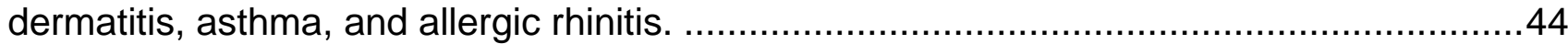

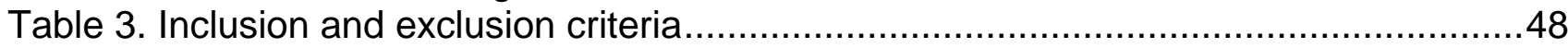

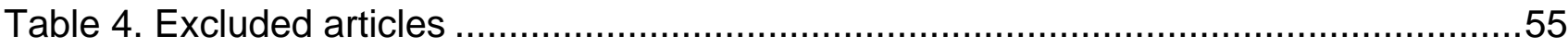

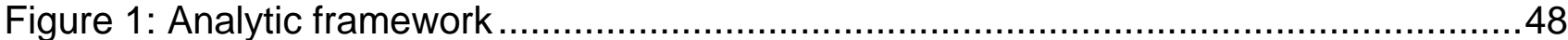

Figure 2: Flow chart of literature search and screening results ....................................54 


\section{INTRODUCTION}

This document describes a systematic review conducted to answer the following question: What is the relationship between timing of introduction of complementary foods and beverages (CFB) and food allergy, atopic dermatitis/eczema, asthma, and allergic rhinitis? This systematic review was conducted as part of the Pregnancy and Birth to 24 Months (P/B-24) Project by USDA's Nutrition Evidence Systematic Review (NESR).

The purpose of the P/B-24 Project was to conduct a series of systematic reviews on diet and health for women who are pregnant and for infants and toddlers from birth to 24 months of age. This project was a joint initiative led by USDA and HHS, and USDA's NESR carried out all of the systematic reviews. A Federal Expert Group (FEG), a broadly representative group of Federal researchers and program leaders, also provided input throughout the P/B-24 Project. More information about the P/B-24 Project has been published ${ }^{2}$ and is available on the NESR website:

https://nesr.usda.gov/project-specific-overview-pb-24-0.

NESR, formerly known as the Nutrition Evidence Library (NEL), specializes in conducting food- and nutrition-related systematic reviews using a rigorous, protocoldriven methodology. To conduct each P/B-24 systematic review, NESR's staff worked with a Technical Expert Collaborative (TEC), which is a group of 7-8 leading subject matter experts.

NESR's systematic review methodology involves developing and prioritizing systematic review questions, searching for and selecting studies, extracting and assessing the risk of bias of data from each included study, synthesizing the evidence, developing a conclusion statement, grading the evidence underlying the conclusion statement, and recommending future research. A detailed description of the methodology used in conducting systematic reviews for the P/B-24 Project has been published ${ }^{3}$ and is available on the NESR website: https://nesr.usda.gov/pb-24-project-methodology-0. In addition, starting on page 47 , this document includes details about the methodology as it was applied to the systematic review described herein. An analytic framework that illustrates the overall scope of the question, including the population, the interventions and/or exposures, comparators, and outcomes of interest, is found on page 47 . In addition, the literature search plan that was used to identify studies included in this systematic review is found on page 49.

\footnotetext{
2 Stoody EE, Spahn JM, Casavale KO. The Pregnancy and Birth to 24 Months Project: a series of systematic reviews on diet and health. Am J Clin Nutr. 2019;109(7):685S-97S. doi: 10.1093/ajcn/nqy372. ${ }_{3}^{3}$ Obbagy JE, Spahn JM, Wong YP, Psota TL, Spill MK, Dreibelbis C, et al. Systematic review methodology used in the Pregnancy and Birth to 24 Months Project. Am J Clin Nutr. 2019;109(7):698S704S. doi: 10.1093/ajcn/nqy226.
} 


\section{List of abbreviations}

\begin{tabular}{ll}
\hline Abbreviation & Full name \\
\hline BF & Breastfed \\
\hline CF & Complementary feeding \\
\hline CFB & Complementary foods and beverages \\
\hline FEG & Federal Expert Group \\
\hline FF & Formula fed \\
\hline HHS & Department of Health and Human Services \\
\hline IgE & Immunoglobulin E \\
\hline NEL & Nutrition Evidence Library \\
\hline NESR & Nutrition Evidence Systematic Review \\
\hline NIH & National Institutes of Health \\
\hline P/B-24 & Pregnancy and Birth to 24 Months Project \\
\hline RCT & Randomized controlled trial \\
\hline TEC & Technical Expert Collaborative \\
\hline USDA & United States Department of Agriculture \\
\hline
\end{tabular}




\section{WHAT IS THE RELATIONSHIP BETWEEN TIMING OF INTRODUCTION OF COMPLEMENTARY FOODS AND BEVERAGES (CFB) AND FOOD ALLERGY, ATOPIC DERMATITIS/ECZEMA, ASTHMA, AND ALLERGIC RHINITIS?}

\section{PLAIN LANGUAGE SUMMARY}

What is the question?

- The question is: What is the relationship between timing of introduction of complementary foods and beverages and food allergy, atopic dermatitis/eczema, asthma, and allergic rhinitis?

What is the answer to the question?

- Moderate evidence suggests that there is no relationship between the age at which complementary feeding first begins and risk of developing food allergy, atopic dermatitis/eczema, or asthma during childhood.

- There is insufficient evidence to determine the relationship between the age at which complementary foods or beverages are first introduced and risk of developing allergic rhinitis during childhood.

\section{Why was this question asked?}

- This important public health question was identified and prioritized as part of the U.S. Department of Agriculture and Department of Health and Human Services Pregnancy and Birth to 24 Months Project.

\section{How was this question answered?}

- A team of Nutrition Evidence Systematic Review staff conducted a systematic review in collaboration with a group of experts called a Technical Expert Collaborative

What is the population of interest?

- Generally healthy infants and toddlers who were fed complementary foods and beverages from ages 0-24 months and had food allergy, atopic dermatitis/eczema, asthma, and allergic rhinitis examined through 18 years of age.

\section{What evidence was found?}

- This review includes 31 studies.

- These studies looked at the age when a complementary food or beverage was first introduced to the infant were first introduced and food allergy, atopic dermatitis/eczema, asthma, or allergic rhinitis.

- Complementary foods and beverages are foods and beverages other than human milk or infant formula provided to an infant or young child.

- Most evidence reported no relationship between age of complementary food 
or beverage introduction and outcomes.

- There are limitations in the evidence as follows: use of less reliable methods to measure outcomes, only a few studies were done for some types of foods and/or outcomes, and other factors that may have had an impact on results were not always accounted for.

\section{How up-to-date is this review?}

This review includes literature from 1/1980 to 2/2017. 


\section{TECHNICAL ABSTRACT}

\section{Background}

- Complementary feeding is the process that starts when human milk or infant formula is complemented by other foods and beverages, beginning during infancy and typically continuing to 24 months of age.

- This systematic review was conducted by a team of Nutrition Evidence Systematic Review (NESR) staff as part of the U.S. Department of Agriculture and Department of Health and Human Services Pregnancy and Birth to 24 Months Project.

- The goal of this systematic review was to answer the following research question: What is the relationship between timing of introduction of complementary foods/beverages and food allergy, atopic dermatitis/eczema, asthma, and allergic rhinitis?

\section{Conclusion Statement and Grades}

- Moderate evidence suggests that there is no relationship between the age at which complementary feeding first begins and risk of developing food allergy, atopic dermatitis/eczema, or asthma during childhood. Grade: Moderate

- There is insufficient evidence to determine the relationship between the age at which complementary foods or beverages are first introduced and risk of developing allergic rhinitis during childhood. Grade: Grade Not Assignable

\section{Methods}

- This systematic review was conducted by a team of staff from NESR in collaboration with a Technical Expert Collaborative.

- A literature search was conducted using 4 databases (CINAHL, Cochrane, Embase, and PubMed) to identify articles published from January 1980 to February 2017 that examined the age when complementary foods and beverages (CFB) were first introduced and food allergy, atopic dermatitis/eczema, asthma, and allergic rhinitis. CFB were defined as foods and beverages other than human milk or infant formula provided to an infant or young child. Outcomes included incidence and prevalence of food allergy, atopic dermatitis/eczema, asthma, and allergic rhinitis. A manual search was done to identify articles that may not have been included in the electronic databases searched. Articles were screened in a dual manner, independently by 2 NESR analysts, to determine which articles met predetermined criteria for inclusion.

- Data from each included article were extracted, risk of bias was assessed. The body of evidence was qualitatively synthesized, a conclusion statement was developed and the strength of the evidence (grade) was assessed using pre-established criteria including evaluation of the internal validity/risk of bias, adequacy, consistency, impact, and generalizability of available evidence. Research recommendations were identified.

\section{Summary of Evidence}


- Thirty-one observational studies are included in this systematic review, having examined the relationship between the age of first introduction to a CFB and risk of food allergies, atopic dermatitis/eczema, asthma, and allergic rhinitis occurring during childhood through 18 years of age.

0 The studies included in this review examined the timing of introduction to CFB, or the age at which infants were first introduced to any foods or beverages other than human milk or infant formula were first introduced to an infant. (Note: Studies that examined the timing of introduction of specific types of CFB, including common allergenic foods, such as peanuts, eggs, and fish, are addressed in a separate review).

o These studies did not specify what food or beverage was first introduced. However, highly allergenic foods are not typically the first CFB introduced into an infant's diet; therefore, it is likely that the studies in this body of evidence reflect the first introduction of cereals, fruits, and vegetables.

o Nine studies examined risk of food allergy, 20 studies examined risk of eczema or atopic dermatitis, eight studies examined risk of asthma, and four studies examined risk of allergic rhinitis.

- Most evidence reported no significant associations between age of CFB introduction and risk of food allergy. While some evidence suggested that earlier first introduction of CFB may be associated with increased risk of developing food allergy, confidence in the results was restricted by methodological limitations.

- The ability to draw stronger conclusions about the relationship between the timing of first introduction to CFB and the risk of atopic disease is due to several limitations:

o Use of non-validated or unreliable measures to assess risk of atopic disease (e.g., parent report of a physician diagnosis or the child's symptoms), and assessment of outcomes later in childhood (through 10 years of age), when some atopic diseases, such as eczema, may have already resolved, or very early in childhood (3-4 months), before some atopic diseases may have occurred.

o Lack of adjustment for key confounders such as consumption of human milk and/or human milk substitutes (e.g., cow's milk formula, hydrolyzed infant formula, or fluid cow's milk), parental smoking, and exposure to household pets

- Potential for reverse causality due to baseline atopic disease risk status impacting both the timing and types and amounts of CFB introduced, and risk of developing atopic disease. 


\section{FULL REVIEW}

\section{Systematic review question}

What is the relationship between timing of introduction of complementary foods and beverages (CFB) food allergy, atopic dermatitis/eczema, asthma, and allergic rhinitis?

\section{Conclusion statement}

Moderate evidence suggests that there is no relationship between the age at which complementary feeding first begins and risk of developing food allergy, atopic dermatitis/eczema, or asthma during childhood.

There is insufficient evidence to determine the relationship between the age at which complementary foods or beverages are first introduced and risk of developing allergic rhinitis during childhood.

\section{Grade}

\section{Moderate - Food allergy, atopic dermatitis/eczema, asthma; Grade Not Assignable - Allergic rhinitis}

\section{Summary}

- Thirty-one observational studies are included in this systematic review, having examined the relationship between the age of first introduction to a CFB and risk of food allergies, atopic dermatitis/eczema, asthma, and allergic rhinitis occurring during childhood through 18 years of age.

0 The studies included in this review examined the timing of introduction to CFB, or the age at which infants were first introduced to any foods or beverages other than human milk or infant formula were first introduced to an infant. (Note: Studies that examined the timing of introduction of specific types of CFB, including common allergenic foods, such as peanuts, eggs, and fish, are addressed in a separate review $^{4}$ ).

o These studies did not specify what food or beverage was first introduced. However, highly allergenic foods are not typically the first CFB introduced into an infant's diet; therefore, it is likely that the studies in this body of evidence reflect the first introduction of cereals, fruits, and vegetables.

o Nine studies examined risk of food allergy, 20 studies examined risk of eczema or atopic dermatitis, eight studies examined risk of asthma, and four studies examined risk of allergic rhinitis.

- Most evidence reported no significant associations between age of CFB

\footnotetext{
${ }^{4}$ Another systematic review examined the relationship between specific types and amounts of foods consumed during the complementary feeding period and risk of food allergies, atopic dermatitis/eczema, asthma, and allergic rhinitis. The timing of introduction of specific types of CFB (e.g., peanuts, eggs, fish) are addressed in that review.
} 
introduction and risk of food allergy. While some evidence suggested that earlier first introduction of CFB may be associated with increased risk of developing food allergy, confidence in the results was restricted by methodological limitations.

- The ability to draw stronger conclusions about the relationship between the timing of first introduction to CFB and the risk of atopic disease is due to several limitations:

o Use of non-validated or unreliable measures to assess risk of atopic disease (e.g., parent report of a physician diagnosis or the child's symptoms), and assessment of outcomes later in childhood (through 10 years of age), when some atopic diseases, such as eczema, may have already resolved, or very early in childhood (3-4 months), before some atopic diseases may have occurred.

o Lack of adjustment for key confounders such as consumption of human milk and/or human milk substitutes (e.g., cow's milk formula, hydrolyzed infant formula, or fluid cow's milk), parental smoking, and exposure to household pets

- Potential for reverse causality due to baseline atopic disease risk status impacting both the timing and types and amounts of CFB introduced, and risk of developing atopic disease.

\section{Description of the evidence}

Thirty-one studies are included in the systematic review examining the relationship between timing of first introduction to any CFB and risk of one or more of the following: food allergy, atopic dermatitis, asthma, and allergic rhinitis occurring during childhood through 18 years $(\mathrm{y})$ of age (Table 1). This table summarizes the results for each of the atopic diseases considered, and therefore, references may be repeated if they report results for two or more outcomes.

Timing of first CFB introduction was measured in a similar way across all studies, by determining the age at which a food or beverage other than human milk or infant formula was first introduced to the infant. These studies did not specify which specific CFB were introduced, but examined the age at which CF first began. However, since highly allergenic foods are not typically the first CFB introduced into an infant's diet in the US, it is likely that the studies in this body of evidence reflect the first introduction of cereals, fruits, and vegetables. Studies did differ in terms of whether timing was analyzed as a categorical or continuous variable, what categories of ages were evaluated, and the methods used for determining age of any CFB introduction. Most studies used introduction of any CFB before 3 or 4 mo as the earliest category, and after 6 mo as the latest category, though categories ranged from introducing CFB before 8 weeks (wk) to introduction between 7 and 12 mo of age.

The included studies examined risk of food allergy, atopic dermatitis, asthma, and allergic rhinitis, which were assessed at a range of ages, from infancy through $18 \mathrm{y}$ of age, using varied diagnostic methods, as described below and in Table 1. 


\section{Summary of findings}

\section{Food allergy}

Nine studies included in this systematic review examined the relationship between timing of first CFB introduction and risk of developing food allergy, including 7 prospective cohort studies (1-7) and 2 nested case-control studies (8, 9) (Table 2). Data from the following cohorts were examined in multiple studies: the Prevalence of Infant Food Allergy EuroPrevall (United Kingdom) study $(8,9)$, and an unnamed Finnish cohort $(2,3)$. Most studies either exclusively enrolled or enrolled a majority of subjects who were at high risk for developing atopic disease based on family history (parent or sibling) of atopic disease (1-3, 5-7). Both studies by Kajosaari et al. $(2,3)$ also exclusively enrolled breast fed (BF) infants, while the other studies included subjects who were BF, formula-fed (FF), or mixed-fed.

The studies used various methods and criteria for diagnosing food allergy, though most studies applied multiple valid and reliable methods, including food challenges, which are considered to be the best method for determining food allergy, as well as skin prick tests, Immunoglobulin E (IgE) levels, occurrence of symptoms postingestion, and/or elimination diets, and/or food challenges. However, a few studies relied on less valid methods, such as parent report of either symptoms or physician diagnosis to determine food allergy $(3,4)$. Risk of food allergy was determined at various ages, ranging from 6 mo through 6 y of age. Most studies adjusted for a number of key confounders, but a few made no adjustments for potential confounders $(2,3,7)$.

Five studies reported no significant associations between the timing of any CFB introduction and risk of developing food allergy (1, 3-6). Most of these studies assessed risk of food allergy at 5-6 y of age. Four remaining studies reported that earlier introduction of CFB was associated with increased risk of food allergy. Grimshaw et al. (9) reported that CFB were introduced significantly earlier in food allergy cases compared with control infants (18 vs. $20 \mathrm{wk}$ ), and in categorical analyses, that later CFB introduction ( $\geq 17 \mathrm{vs}$. $<17 \mathrm{wk}$ ) was significantly associated with reduced risk of food allergy at $2 \mathrm{y}$. Grimshaw et al. (8) analyzed the same data set, distinguishing between whether the food allergy was IgE-mediated or not, and found that earlier CFB introduction was significantly associated with non-IgEmediated food allergy at $2 \mathrm{y}$, but not IgE-mediated food allergy. Kajosaari et al. (2) reported that earlier CFB introduction ( 3 vs. $6 \mathrm{mo}$ ) was significantly associated with increased risk of food allergy at $1 \mathrm{y}$. However, their subsequent publication (3) reported that this association was no longer significant when examining risk of food allergy at $5 \mathrm{y}$. Finally, Venter et al. (7) found that earlier CFB introduction ( $<16 \mathrm{vs.}$ $>16 \mathrm{wk}$ ) was associated with significantly decreased risk of food allergy at $1 \mathrm{y}$ and 3 y. However, this study did not account for any potential confounders.

\section{Atopic dermatitis}

Twenty studies included in this systematic review examined the relationship between timing of CFB introduction and atopic dermatitis, including 19 prospective cohort studies (1-3, 6, 10-24) and 1 case-control study (25) (Table 2). Data from the following cohorts were examined in multiple studies, in which outcomes were 
assessed in the same group of participants, but at different ages: the LifestyleRelated Factors on the Immune System and the Development of Allergy in Childhood (Germany) study $(23,24)$, the German Infant Nutritional Intervention Program $(12,19)$, and an unnamed Finnish cohort $(2,3)$.

Half of the studies included a majority of subjects who were considered to be at high risk for atopic disease, having a family history (parent or sibling) of atopic disease $(1-3,6,14,16,18,20,22-24)$, though most controlled for risk status in analyses (1, $6,14,16,20,23,24)$. Kajosaari et al. $(2,3)$ also exclusively enrolled BF infants, while the other studies included subjects who were BF, FF, or mixed fed.

There was variability among studies in the methods and criteria used for diagnosing atopic dermatitis. Four studies based outcome assessment on a clinical exam done by study personnel $(1,3,18,19)$. However, most relied on less valid and/or reliable methods of parent report of symptoms or report of physician diagnosis. Age of outcome assessment occurred between 1 y and 6 y of age. Most studies adjusted for a number of key confounders, but several adjusted for only a few, or no potential confounders $(2,3,11,18,22,25)$.

Fifteen of the 20 studies reported no significant associations between timing of first CFB introduction and risk of developing atopic dermatitis $(1,3,6,10,12,14-19,22-$ 25).

The results from the studies that reported significant associations between timing of CFB introduction and risk of atopic dermatitis were mixed. Two studies found that earlier introduction of CFB was associated with increased risk of atopic dermatitis. Fergusson et al. (11) reported that earlier introduction of CFB ( $<4 \mathrm{vs} .>4 \mathrm{mo}$ ) was significantly associated with increased risk of atopic dermatitis at $2 \mathrm{y}$. Kajosaari et al. (2) found that earlier CFB introduction (3 vs. $6 \mathrm{mo}$ ) was significantly associated with increased risk of atopic dematitis at $1 \mathrm{y}$. Two studies found that later introduction of CFB was significantly associated with increased risk of atopic dermatitis. Snijders et al. (20) found that later CFB introduction was significantly associated with increased risk of atopic dermatitis ( 3 vs 4-6 mo and 3 vs $>7 \mathrm{mo}$ ) at $2 \mathrm{y}$. Taylor-Robinson et al. (21) found that later CFB introduction ( $>4 \mathrm{vs} .<4 \mathrm{mo}$ ) was significantly associated with increased risk of atopic dermatitis at $5 \mathrm{y}$. Finally, Forsyth et al. (13) found that introducing CFB between 8-12 wk (vs. $<8$ or $>12$ wk) was significantly associated with greater incidence of atopic dermatitis between 53104 wk.

In some of the studies that examined data from the same cohort, but measured outcomes at different ages, results were the same regardless of when the outcome was assessed $(12,19,23,24)$. However, 1 study reported that earlier CFB introduction was associated with increased risk of atopic dermatitis at 1 y (2), but this association was no longer significant at 5 y (3).

\section{Asthma}

Eight studies, including 7 prospective cohort studies and 1 case-control study, examined the relationship between timing of CFB introduction and asthma $(3,6,16$, 24, 26-29) (Table 2). Three of these studies exclusively enrolled subjects who were 
at high risk for developing atopic disease, with all subjects having a family history (parent or sibling) of atopic disease $(3,6,16)$. Kajosaari et al. (3) also exclusively enrolled BF infants, while the other studies included subjects who were BF, FF, or mixed-fed. The studies used similar methods and criteria for diagnosing asthma, relying primarily on parent report of symptoms, with only 2 studies using a physician to diagnose asthma $(6,28)$. Age of outcome assessment occurred between $2 \mathrm{y}$ and $15 \mathrm{y}$, with most assessing outcomes between $4 \mathrm{y}$ and $7 \mathrm{y}$ of age. Most studies adjusted for a number of key confounders, but Kajosaari et al. (3) did not make any adjustments for potential confounders.

Seven of the 8 studies reported no significant associations between age of CFB introduction and asthma $(3,6,16,24,26,27,29)$. In a case-control study conducted in Malaysia, Nathan et al. (28) found that children with asthma (ages 3-15 y) were significantly more likely to have had earlier introduction of CFB ( $<6 \mathrm{vs}$. $>6 \mathrm{mo}$ ) than control children without asthma. However, this study had a number of limitations, including lack of control for several key confounders (education, SES, race/ethnicity, birth size), and use of non-validated, unreliable measures for assessing the timing of CFB introduction, which introduced the potential for recall bias, particularly among subjects recruited at older ages.

\section{Allergic rhinitis}

Four prospective cohort studies included in this review examined the relationship between timing of CFB introduction and allergic rhinitis $(3,6,22,24)$ (Table 2). Three of these studies exclusively enrolled subjects who were at high risk for developing atopic disease, with all subjects having a family history (parent or sibling) of atopic disease $(3,6,22)$. Kajosaari et al. (3) enrolled exclusively BF infants, while the other studies included subjects who were BF, FF, or mixed-fed. As there are no standardized criteria for diagnosing allergic rhinitis, other than the presence of typical symptoms and corresponding positive skin prick tests, these studies are difficult to evaluate, as all relied on parent report of symptoms only. Age of outcome assessment occurred at 20 mo to 2 y $(6,22)$ or $5-6$ y of age $(3,6,24)$. Neither Kajosaari et al. (3) or Van Asperen et al. (22) adjusted for any potential confounders.

Most studies reported no significant associations between age of any CFB introduction and allergic rhinitis at $20 \mathrm{mo}(22), 2$ y (6), 5 y (6), or 6 y (24). Kajosaari et al. (3) reported that earlier introduction of solids ( $3 \mathrm{vs} .6 \mathrm{mo}$ ) was significantly associated with increased risk of allergic rhinitis at $5 \mathrm{y}$. However, allergic rhinitis was based on parent report of symptoms, and no adjustments were made for potential confounders.

\section{Atopic disease}

Three studies, including 2 prospective cohort studies $(3,30)$ and 1 case-control study (31), examined the relationship between timing of CFB introduction and atopic disease in general (Table 2). This category included studies that found 2 or more atopic diseases in the same subject. Two of these studies exclusively enrolled subjects who were at high risk for developing atopic disease, with all subjects having a family history (parent or sibling) of atopic disease $(3,30)$. Kajosaari et al. 
(3) enrolled exclusively BF infants, while Poysa et al. (30) and Yung et al. (31) included subjects who were BF, FF, or mixed-fed. The studies varied in terms of the atopic diseases considered, diagnostic methods used, and ages when outcomes were assessed, with most relying on parent report of symptoms or a physician diagnosis. Finally, none of the studies adjusted for any potential key confounders.

All 3 studies reported no significant associations between age of CFB introduction and atopic disease, including atopic dermatitis, asthma, allergic rhinitis, and/or allergies (dust mite, food, drug, etc.) at $21 \mathrm{mo}$ (31); atopic dermatitis, asthma, and/or positive skin prick test corresponding with history of food, pollen, or animal dander (birch, alm, timothy, mugwort, dog and cat epithelium, fish, milk, and wheat) at 5 y (3), or asthma, allergic rhinitis, allergic conjunctivitis, atopic dermatitis, and/or food allergy at 9 y (30).

\section{Evidence synthesis}

Overall, moderate evidence suggests that there is no relationship between the age at which complementary feeding first begins and risk of developing food allergy, atopic dermatitis, or asthma during childhood. However, there is not enough evidence to determine whether there is a relationship with risk of developing allergic rhinitis.

Most of the evidence suggests no relationship between age of the first CFB introduction and risk of food allergy. While there is some evidence to suggest that earlier first introduction of CFB may be associated with increased risk of developing food allergy, confidence is limited by the use of the same cohort in multiple studies and concerns about the validity and reliability of methods used to assess food allergy. In addition, some studies did not account for one or more key confounders, or the specific types of CFB that were being introduced. Similarly, the preponderance of evidence suggests that there is no relationship between the age of first introduction to CFB and risk of developing atopic dermatitis and asthma. Finally, due to an inadequate number of studies with key methodological issues, it is not possible to draw conclusions about the relationship between age of CFB introduction and risk of developing allergic rhinitis.

There were several common methological limitations that could potentially lower the internal validity of the studies and reduce confidence in the findings. A number of studies used non-validated or unreliable measures (e.g., parent report of a child's symptoms, or parent report of a physician diagnosis) to assess risk of atopic disease, particularly atopic dermatitis, asthma, and allergic rhinitis. In some cases, outcomes were assessed at inappropriate ages. For example, outcome assessment sometimes occurred later in childhood (through 10 years of age), when some atopic diseases, such as atopic dermatitis, may have already resolved, or very early in infancy (3-4 months), before atopic diseases may have emerged. In addition, there was a lack of adjustment for key confounders, such as infant milk feeding practices (e.g., human milk, cow's milk formula, hydrolyzed infant formula, or fluid cow's milk), parental smoking, exposure to household pets, and the types of CFB introduced.

Subjects in the studies are generalizable to the U.S. population. The studies were 
conducted in a number of countries that were all determined to be "very high" or "high" according to the 2014 Human Development Index (HDI, 2014). Six studies were conducted in the United Kingdom, 5 each in Finland and Germany, 4 in the US, 3 in Australia, 2 in New Zealand, and 1 study each from Hong Kong, Malaysia, Mexico, Sweden, Taiwan, and the Netherlands.

However, because many of the studies included in this review exclusively enrolled or enrolled a majority of subjects who were at higher risk than the general population for developing allergy and/or atopic disease based on family history of atopic disease, the potential for reverse causality needs to be considered. Having a family background of atopic disease, such as 1 or both parents or a sibling with a diagnosed atopic disease, is 1 of the key risk factors for development of atopic diseases. In addition, known risk status could impact the timing, types, and amounts of CFB that were introduced, as well as risk of developing various atopic diseases in early childhood. However, despite the inclusion of higher risk populations in this body of evidence, the results are probably generalizable to infants and toddlers who are lower risk for atopic disease. In addition, most studies adjusted for atopy risk status in analyses.

\section{Research recommendations}

In order to better assess the relationship between CF and risk of atopic disease, additional research is needed that:

- Includes well-designed, targeted RCTs that address specific knowledge gaps

- Uses valid and reliable methods to assess infants' dietary intake and established criteria, testing, and/or biomarkers to diagnose atopic disease at ages appropriate to the typical presentation of the disease

- Adjusts for key confounders, including infant milk feeding practices (e.g., human milk, cow's milk formula, hydrolyzed infant formula, or fluid cow's milk), parental smoking, exposure to household pets, and the types of CFB introduced

- Accounts for potential reverse causality by considering subjects' baseline risk status for atopic disease

- Uses standard, consistent definitions of diet diversity, both in terms of the numbers and types of foods and food groups considered

- Considers the mechanisms by which specific types of foods, diet diversity, and dietary patterns may affect risk of developing atopic disease when determining which diet-health relationships to investigate, and what analyses are appropriate 


\section{Included articles}

1. Hesselmar, B, Saalman, R, Rudin, A, Adlerberth, I, Wold, A. Early fish introduction is associated with less eczema, but not sensitization, in infants. Acta Paediatr 2010;99:1861-7.

2. Kajosaari, M, Saarinen, U M. Prophylaxis of atopic disease by six months' total solid food elimination. Evaluation of 135 exclusively breast-fed infants of atopic families. Acta Paediatr Scand 1983;72:411-4.

3. Kajosaari, M. Atopy prevention in childhood: the role of diet. Prospective 5-year follow-up of high-risk infants with six months exclusive breastfeeding and solid food elimination. Pediatr Allergy Immunol 1994;5:26-8.

4. Luccioli, S, Zhang, Y, Verrill, L, Ramos V, M, Kwegyir A, E. Infant feeding practices and reported food allergies at 6 years of age. Pediatrics 2014.

5. McGowan, E C, Bloomberg, G R, Gergen, P J, Visness, C M, Jaffee, K F, et al. Influence of early-life exposures on food sensitization and food allergy in an inner-city birth cohort. J Allergy Clin Immunol 2015;135:171-8.

6. Sandini U, Kukkonen AK, Poussa T, Sandini L, Savilahti E, Kuitunen M. Protective and risk factors for allergic diseases in high-risk children at the ages of two and five years. Int Arch Allergy Immunol 2011;156(3):339-48.

7. Venter, C, Pereira, B, Voigt, K, Grundy, J, Clayton, C B, et al. Factors associated with maternal dietary intake, feeding and weaning practices, and the development of food hypersensitivity in the infant. Pediatr Allergy Immunol 2009;20:320-7.

8. Grimshaw, K E, Bryant, T, Oliver, E M, Martin, J, Maskell, J, et al. Incidence and risk factors for food hypersensitivity in UK infants: results from a birth cohort study. Clin Transl Allergy 2015;6:1.

9. Grimshaw, K E, Maskell, J, Oliver, E M, Morris, R C, Foote, K D, et al. Introduction of complementary foods and the relationship to food allergy. Pediatrics 2013;132. 10. Chuang, C H, Hsieh, W S, Chen, Y C, Chang, P J, Hurng, B S, et al. Infant feeding practices and physician diagnosed atopic dermatitis: a prospective cohort study in Taiwan. Pediatr Allergy Immunol 2011;22:43-9.

11. Fergusson, D M, Horwood, L J, Beautrais, A L, Shannon, F T, Taylor, B. Eczema and infant diet. Clin Allergy 1981;11:325-31.

12. Filipiak, B, Zutavern, A, Koletzko, S, von B, A, Brockow, I, et al. Solid food introduction in relation to eczema: results from a four-year prospective birth cohort study. J Pediatr 2007;151:352-8.

13. Forsyth, J S, Ogston, S A, Clark, A, Florey, C D, Howie, P W. Relation between early introduction of solid food to infants and their weight and illnesses during the first two years of life. Bmj 1993;306(6892):1572-6.

14. Illi S, von Mutius E, Lau S, Nickel R, Gruber C, Niggemann B, Wahn U. The natural course of atopic dermatitis from birth to age 7 years and the association with asthma. $J$ Allergy Clin Immunol 2004;113(5):925-31.

15. Joseph, C L, Ownby, D R, Havstad, S L, Woodcroft, K J, Wegienka, G, et al. Early complementary feeding and risk of food sensitization in a birth cohort. J Allergy Clin Immunol 2011;127.

16. Mihrshahi, S, Ampon, R, Webb, K, Almqvist, C, Kemp, A S, et al. The association between infant feeding practices and subsequent atopy among children with a family history of asthma. Clin Exp Allergy 2007;37:671-9. 
17. O'Donovan, S M, O'B H, Murray, D M, Kenny, L C, Khashan, A S, Chaoimh, et al. Neonatal adiposity increases the risk of atopic dermatitis during the first year of life. $J$ Allergy Clin Immunol 2016;137:108-17.

18. Poysa, L, Remes, K, Korppi, M, Juntunen B, K. Atopy in children with and without a family history of atopy. I. Clinical manifestations, with special reference to diet in infancy. Acta Paediatr Scand 1989;78:896-901.

19. Schoetzau, A, Filipiak P, B, Franke, K, Koletzko, S, Von B, A, et al. Effect of exclusive breast-feeding and early solid food avoidance on the incidence of atopic dermatitis in high-risk infants at 1 year of age. Pediatr Allergy Immunol 2002;13:234-42. 20. Snijders, B E, Thijs, C, van R, R, van den B, P A. Age at first introduction of cow milk products and other food products in relation to infant atopic manifestations in the first 2 years of life: the KOALA Birth Cohort Study. Pediatrics 2008;122.

21. Taylor R, D C, Williams, H, Pearce, A, Law, C, Hope, S. Do early-life exposures explain why more advantaged children get eczema? Findings from the U.K. Millennium Cohort Study. Br J Dermatol 2016;174:569-78.

22. Van A, P P, Kemp, A S, Mellis, C M. Relationship of diet in the development of atopy in infancy. Clin Allergy 1984;14:525-32.

23. Zutavern, A, Brockow, I, Schaaf, B, Bolte, G, von B, A, et al. Timing of solid food introduction in relation to atopic dermatitis and atopic sensitization: results from a prospective birth cohort study. Pediatrics 2006;117:401-11.

24.Zutavern, A, Brockow, I, Schaaf, B, von B, A, Diez, U, et al. Timing of solid food introduction in relation to eczema, asthma, allergic rhinitis, and food and inhalant sensitization at the age of 6 years: results from the prospective birth cohort study LISA. Pediatrics 2008;121.

25. Estrada R, E, Pardo C, M G, Toledo B, M E, Lerma O, M L, del R-N, B, et al. A case-control study of food hyper-sensitivity, timing of weaning and family history of allergies in young children with atopic dermatitis. Allergol Immunopathol (Madr) 2007;35:101-4.

26. Fergusson, D M, Horwood, L J, Shannon, F T. Asthma and infant diet. Arch Dis Child 1983;58:48-51.

27. Hetzner, N M, Razza, R A, Malone, L M, Brooks G, J. Associations among feeding behaviors during infancy and child illness at two years. Matern Child Health $\mathrm{J}$ 2009;13:795-805.

28. Nathan, A M, de B, J, Khalid, F, Arumugam, K. Caesarean section and asthma in Malaysian children: a case-control study. Asian Pac J Allergy Immunol 2012;30:204-8. 29. Wilson, A C, Forsyth, J S, Greene, S A, Irvine, L, Hau, C, et al. Relation of infant diet to childhood health: seven year follow up of cohort of children in Dundee infant feeding study. Bmj 1998;316(7124):21-5.

30. Poysa, L, Korppi, M, Remes, K, Juntunen B, K. Atopy in childhood and diet in infancy. A nine-year follow-up study. I. Clinical manifestations. Allergy Proc 1991;12:107-11.

31. Yung, J, Yuen, J W, Ou, Y, Loke, A Y. Factors associated with atopy in toddlers: a case-control study. Int J Environ Res Public Health 2015;12:2501-20.

32. United Nations Development Programme. Human Development Report 2014. Sustaining Human Progress: Reducing Vulnerabilities and Building Resilience. New York, 2014. 
33. The World Bank. Internet:

https://datahelpdesk.worldbank.org/knowledgebase/articles/906519-world-bankcountry-and-lending-groups (accessed March 27, 2018). 
Table 1. Description of studies examining the relationship between the timing of introduction of complementary foods and beverages (CFB) and food allergy, atopic dermatitis/eczema, asthma, and allergic rhinitis.

\section{References; Subject Characteristics (Sample \\ Size, Sex, Race/Ethnicity, Atopic Disease Risk Status; Background Diet) \\ Chuang, 2011}

Prospective Cohort Study; Taiwan (Taiwan Birth Cohort Study)

Sample Size:

Baseline N: 24200

Analytic N: 18733

Attrition: 23\%

Sample Size Calculation: NR

Sex: $48 \%$ Female

Race/Ethnicity: NR

Atopic Disease Risk Status: 30\% had parental allergic history; excluded children with doctordiagnosed atopic dermatitis from 0-6mo

Background Diet: $26.9 \%$ BF within 1mo

\section{Estrada-Reyes, 2007}

Case-Control Study; Mexico

Sample Size:

Cases: 28

Controls: 28

\section{Independent Variable/Exposure, Outcomes}

Intervention/Exposure:

Age of CFB introduction: <4, 4-6, >6mo

Assessment Methods: Maternal interview

Outcomes:

Atopic dermatitis

Age: $18 \mathrm{mo}$

Assessment Methods:

Atopic dermatitis: Maternal report of physician diagnosis

\section{Confounders, Limitations}

Confounders:

The following confounders were accounted for: Education; Sex; Feeding practices; Birth size; Gestational age; Smoking; Atopy risk status; Pets in home; Mold in home; Birth order; Parent age; Residence

\section{Limitations:}

Cannot determine whether groups were similar at baseline on key characteristics

Did not account for high attrition

Outcome assessors were not blinded

Did not use valid/reliable methods for assessing outcomes (parent report)

Did not adjust for key confounders (SES, race/ethnicity) Limited generalizability due to enrollment of population at high risk for atopic disease

Confounders:

Intervention/Exposure:

Age of CFB introduction: $<6,>6 \mathrm{mo}$

Assessment Methods: Maternal interview

The following confounders were accounted for: Atopy risk status

Limitations:

Outcomes:

Atopic dermatitis

Cannot determine whether groups were similar at baseline on key characteristics 


\section{References; Subject Characteristics (Sample Size, Sex, Race/Ethnicity, Atopic Disease Risk Status; Background Diet)}

Attrition: 0\%

Sample Size Calculation: NR

Sex: $50 \%$ Female

Race/Ethnicity: NR

Atopic Disease Risk Status: $45 \%$ had family allergic history

Background Diet: NR

\section{Fergusson, 1981}

Prospective Cohort Study; New Zealand (Christchurch Health and Development Study)

Sample Size:

Baseline N: 1262

Analytic N: 1156

Attrition: 8\%

Sample Size Calculation: NR

Sex: NR

Race/Ethnicity: NR

Atopic Disease Risk Status: 24\% had parental atopy history

Background Diet: EBF at 4mo: 19\%

\section{Independent Variable/Exposure, Outcomes} Age: $<3 y$

Assessment Methods:

Atopic dermatitis: Maternal report, confirmed by study personnel

\section{Confounders, Limitations}

Outcome assessors were not blinded

Did not adjust for key confounders (education, SES, sex, race/ethnicity, feeding practices, birth size, gestational age, smoking)

Small sample size; study may have been underpowered
Intervention/Exposure:

Age of CFB introduction: $<4,>4 \mathrm{mo}$

Assessment Methods: Maternal interview, food diary

Outcomes:

Eczema

Age: $2 y$

Assessment Methods:

Eczema: Maternal report; with some physician validation

\section{Confounders:}

The following confounders were accounted for: Feeding practices; Atopy risk status

Limitations:

Cannot determine whether groups were similar at baseline on key characteristics

Cannot determine recruitment methods, baseline characteristics, confounding factors, or blinding methods

Outcome assessors were not blinded

Did not adjust for key confounders (education, SES, sex, race/ethnicity, feeding practices, birth size, gestational age, smoking)

Limited generalizability due to lower rates of exclusive BF that may not be representative of current infant feeding practices

\section{Fergusson, 1983}

Intervention/Exposure:

Prospective Cohort Study; New Zealand (Christchurch Health and Development Study)
Age of CFB introduction: $<4,>4 \mathrm{mo}$

Assessment Methods: Maternal interview, food diary
Confounders:

The following confounders were accounted for: Feeding practices; Atopy risk status 


\section{References; Subject Characteristics (Sample Size, Sex, Race/Ethnicity, Atopic Disease Risk Status; Background Diet)}

\section{Sample Size:}

Baseline N: 1265

Analytic N: 1110

Attrition: $12 \%$

Sample Size Calculation: NR

Sex: NR

Race/Ethnicity: NR

Atopic Disease Risk Status: 11\% had parental asthma history

Background Diet: EBF at 4mo: 19\%

Independent Variable/Exposure, Outcomes

Outcomes:

Asthma

Age: 4y

Assessment Methods:

Asthma: Maternal report of physician diagnosis, or history of wheezy bronchitis, with some physician validation
Filipiak, 2007

Prospective Cohort Study; Germany (German Infant Nutritional Intervention Program)

Sample Size:

Baseline N: 5991 (N: 2252 in intervention group, $\mathrm{N}$ : 3739 in non-intervention group)

Analytic N: 4753

Attrition: $21 \%$

Sample Size Calculation: NR

Sex: NR

Race/Ethnicity: NR

\section{Intervention/Exposure}

Age of CFB introduction: 1-4, 5-6, 7-12mo

Assessment Methods: Parent questionnaire

Outcomes:

\section{Eczema}

Age: $4 y$

Assessment Methods:

Eczema: Parent report of doctor diagnosis or recurrent symptoms lasting for $6 \mathrm{mo}$ up to $1 \mathrm{y}$ and $2 \mathrm{wk}$ at 2-4y

\section{Confounders, Limitations}

\section{Limitations:}

Cannot determine whether groups were similar at baseline on key characteristics

Cannot determine recruitment methods, baseline characteristics, confounding factors, or blinding methods

Outcome assessors were not blinded

Did not use valid/reliable measures to assess outcomes

Did not adjust for key confounders (education, SES, sex, race/ethnicity, birth size, gestational age, smoking)

Limited generalizability due to lower rates of exclusive $\mathrm{BF}$ that may not be representative of current infant feeding practices

\section{Confounders:}

The following confounders were accounted for: Education; Sex; Feeding practices; Birth size; Gestational age; Smoking; Atopy risk status; Study region; siblings; pets)

\section{Limitations:}

Cannot determine whether groups were similar at baseline on key characteristics

Outcome assessors (parent report) were not blinded Outcomes were not assessed using valid measures (parent report of physician diagnosis)

Difficult to determine attrition rates based on sample sizes presented in text/tables 


\section{References; Subject Characteristics (Sample Size, Sex, Race/Ethnicity, Atopic Disease Risk Status; Background Diet)}

Atopic Disease Risk Status: $\sim 22 \%$ had familial history of eczema (40\% in intervention group, 10\% in non-intervention group); $100 \%$ of subjects in the intervention group had family history of atopic disease

Background Diet: EBF at 4mo: 50\%
Forsyth, 1993
Prospective Cohort Study; Scotland

Sample Size:

Analytic N: 544 at 26wk, 548 at 52wk, 392 at 104wk

Attrition: $19 \%$ at $26 \mathrm{wk}$ and $52 \mathrm{wk}, 50 \%$ at $104 \mathrm{wk}$ Sample Size Calculation: NR

Sex: $52 \%$ Female

Race/Ethnicity: NR

Atopic Disease Risk Status: NR

Background Diet: BF at 13wk: 14\% EBF, 19.3\% PBF, 66\% MF

\section{Grimshaw, 2013}

Nested Case-Control Study; United Kingdom (Prevalence of Infant Food Allergy EuroPrevall)

Sample Size:
Baseline N: 671
Independent Variable/Exposure, Outcomes

e

(20)

Did not adjust for key confounders (SES, race/ethnicity, gestational age)

Multi-component intervention may have confounded outcome (randomization to different formulas+ recommendations)

Sample size calculations not reported. Intervention/Exposure:

Age of CFB introduction: <8, 8-12, >12wk

Assessment Methods: Maternal questionnaire

Outcomes:

Eczema

Age: Asthma: 14-26wk

Eczema: 53wk-104wk ( 1-2y)

Assessment Methods:

Eczema: Parent report, medical record review; presence of itchy rash
Confounders:

The following confounders were accounted for: SES; Sex; Feeding practices; Birth size; Smoking; Atopy risk status; Maternal age

\section{Limitations:}

Cannot determine whether groups were similar at baseline on key characteristics

Cannot determine validity/reliability of measures used to assess outcomes

High-attrition (50\%) at 104wk not accounted for in analyses

Did not adjust for key confounders (education, race/ethnicity, gestational age)

Intervention/Exposure:

Age of CFB introduction: Age in weeks, continuous

Assessment Methods: Food diary

\section{Confounders:}

The following confounders were accounted for: Education; Sex; Feeding practices; Smoking; Atopy risk status; Pet ownership; Maternal Age; Single birth 


\section{References; Subject Characteristics (Sample Size, Sex, Race/Ethnicity, Atopic Disease Risk Status; Background Diet)}

\section{Cases: 41}

Controls: 82

Attrition: $0 \%$

Sample Size Calculation: NR

Sex: $46 \%$ Female

Race/Ethnicity: 95\% Caucasian

Atopic Disease Risk Status: $27 \%$ cases vs. $13 \%$ controls had maternal asthma; $54 \%$ vs. $38 \%$ had maternal allergy

Background Diet: 94\% initiated BF, 50\% EBF at 9 weeks; Median BF duration 22wk, Median EBF

duration $7 \mathrm{wk}$; CFB introduced at 20.3wk

\section{Grimshaw, 2016}

Nested Case-Control Study; United Kingdom (Prevalence of Infant Food Allergy EuroPrevall)

\section{Sample Size:}

Cases: 41

Controls: 82

Attrition: $0 \%$

Sample Size Calculation: NR

Sex: $49 \%$ Female

Race/Ethnicity: 95\% Caucasian

Atopic Disease Risk Status: $67 \%$ had maternal atopy; $54 \%$ had paternal atopy; $22 \%$ had maternal food allergy; $12 \%$ had paternal food allergy

\section{Independent Variable/Exposure, Outcomes}

Food allergy

Age: $2 y$

Assessment Methods:

Food allergy: Parent report with clinical history, $\lg \mathrm{E} \geq 0.35$ and/or SPT wheal $\geq 3 \mathrm{~mm}$; exclusion diet with improved symptoms; and DBPCFC (including delayed reactions up to $48 \mathrm{hr}$ after the challenge)

\section{Confounders, Limitations}

Cannot determine whether participants were similar at baseline on key characteristics

Did not adjust for key confounders (SES, race/ethnicity, birth size, gestational age)

Small sample size; study may have been underpowered

\section{Intervention/Exposure:}

Age of CFB introduction: Age in weeks, continuous

Assessment Methods: Food diary

Outcomes:

Food allergy (IgE and non-IgE mediated)

Age: $2 \mathrm{y}$

Assessment Methods:

Food allergy: Parent report with clinical history, $\lg \mathrm{E} \geq 0.35$ and/or SPT wheal $\geq 3 \mathrm{~mm}$; exclusion diet with improved symptoms; and DBPCFC (including delayed reactions up to $48 \mathrm{hr}$ after the challenge)

\section{Confounders:}

The following confounders were accounted for: Gestational age; Atopy risk status; Child age; Dog at home; Received skin creams, powders, lotions; No nut/peanut intake during pregnancy; Reduced soy intake during $\mathrm{BF}$

\section{Limitations:}

Cannot determine whether participants were similar at baseline on key characteristics

Did not adjust for key confounders (SES, pets)

Small sample size; study may have been underpowered 


\section{References; Subject Characteristics (Sample \\ Size, Sex, Race/Ethnicity, Atopic Disease Risk \\ Status; Background Diet)}

Independent Variable/Exposure, Outcomes

Confounders, Limitations

Background Diet: 94\% initiated BF, 50\% EBF at 9

weeks; Median BF duration 22wk, Median EBF

duration 7 wk; CFB introduced at 20.3wk

Hesselmar, 2010

Prospective Cohort Study; Sweden (ALLERGYFLORA)

Sample Size:

Baseline N: 207

Analytic N: 184

Attrition: $11 \%$

Sample Size Calculation: NR

Sex: $50 \%$ Female

Race/Ethnicity: NR

Atopic Disease Risk Status: 80\% had both parents, $49 \%$ maternal, $41 \%$ paternal history of asthma, AR, or eczema

Background Diet: $88 \%$ BF; 76\% still PBF at 6mo; Formula introduced $\sim 5 \mathrm{mo}$; median duration EBF $4 \mathrm{mo}$, PB 7.5mo; Age introduced to solids

(potatoes, root/vegetables, meats) 4mo; fruit 5mo; fish 10mo; hen's egg $12 \mathrm{mo}$

\section{Hetzner, 2009}

Prospective Cohort Study; United States (Early Child Longitudinal Study-Birth Cohort)

Sample Size:

Intervention/Exposure:

Age of CFB introduction: Age in months, continuous

(CFB: potatoes, root vegetables, vegetables, and meat)

Assessment Methods: Food diary

\section{Outcomes:}

Food allergy, eczema, asthma

Age: $18 \mathrm{mo}$

Assessment Methods:

Food allergy: Symptoms (immediate or late-onset reaction) after food ingestion, with OFC, and/or food-specific lgE, SPT wheal $\geq 3 \mathrm{~mm}$, and/or GI biopsy/multi-organ reactions

Eczema: Clinical exam

\section{Confounders:}

The following confounders were accounted for: Sex; Feeding practices; Gestational age; Atopy risk status

\section{Limitations:}

Cannot determine whether participants were similar at baseline on key characteristics of race/ethnicity, SES, education, birth size/weight, or smoking exposure

Cannot determine whether outcome assessors were blinded

Did not adjust for key confounders (education, SES, race/ethnicity, birth size, smoking)

CFB included only "non allergenic" foods; allergenic foods examined seperately

\section{Intervention/Exposure:}

Age of CFB introduction: $<6,>6 \mathrm{mo}$

Assessment Methods: Maternal interview

\section{Confounders:}

The following confounders were accounted for: Education; SES; Sex; Race/ethnicity; Feeding practices; Birth size; Smoking 


\section{References; Subject Characteristics (Sample Size, Sex, Race/Ethnicity, Atopic Disease Risk Status; Background Diet)}

Baseline N: 10700

Analytic N: 7900

Attrition: $26 \%$

Sample Size Calculation: NR

Sex: 49\% Female

Race/Ethnicity: 54\% White-Non Hispanic; 13\% Black-African American-Non Hispanic; 26\%

Hispanic; 3\% Asian

Atopic Disease Risk Status: NR

Background Diet: 70\% initiated BF; 78\% introduced formula $<6 \mathrm{mo} ; 74 \%$ introduced to CFB<6mo; $15 \%$ introduced finger-foods $<6 \mathrm{mo}$

\section{Illi, 2004}

Prospective Cohort Study; German (German Multicenter Atopy Study)

\section{Sample Size:}

Baseline N: 1314

Analytic N: 858

Attrition: $35 \%$

Sample Size Calculation: NR

Sex: NR

Race/Ethnicity: NR

Atopic Disease Risk Status: 73\% had parental atopy history

Background Diet:
Independent Variable/Exposure, Outcomes

Asthma

Age: $2 \mathrm{y}$

Assessment Methods:

Asthma: Maternal report Intervention/Exposure:

Age of CFB introduction: Quartiles (not described)

Assessment Methods: Parent interview

Outcomes:

Atopic dermatitis

Age: $2 y$

Assessment Methods:

Atopic dermatitis: Parent report of physician diagnosis or symptoms; or visible atopic dermatitis at follow-up

\section{Confounders, Limitations}

Cannot determine whether groups were similar at baseline on key characteristics

Outcome assessors were not blinded

Outcome measures used were not valid/reliable (maternal report of asthma with no criteria or definition provided, and at an arly age when asthma diagnoses are less reliable)

Did not adjust for key confounders (gestational age, atopy risk status)

\section{Confounders:}

The following confounders were accounted for:

Education; Sex; Feeding practices; Smoking; Atopy risk status; Pets; older siblings; \# of infectious diseases

\section{Limitations:}

Cannot determine whether participants were similar at baseline on key characteristics of SES, race/ethnicity, birth size, or gestational age

Outcome assessors were not blinded

Outcome measures used were not valid/reliable

Did not adjust for key confounders (SES, race/ethnicity, birth size, gestational age)

Did not describe categories (quartiles) anlyzed for age of CFB introduction; did not show data for analyses wih risk of $A D$, and did not report whether analyses were 
References; Subject Characteristics (Sample

Size, Sex, Race/Ethnicity, Atopic Disease Risk

Status; Background Diet)

92\% initiated BF; $49 \%$ received supplements in

first days of life (36\% of which was cow's milk

formula, often partially hydrolyzed)

53\% introduced CFB <3mo; atopic parents

introduced CFB later than non-atopic parents

\section{Joseph, 2011}

Prospective Cohort Study; United States (Wayne County Health, Environment, Allergy and Asthma

Longitudinal (WHEALS) Study)

\section{Sample Size:}

Baseline N: 1258

Analytic N: 594

Attrition: $53 \%$

Sample Size Calculation: NR

Sex: NR

Race/Ethnicity: 61\% Black

Atopic Disease Risk Status: $45 \%$ had parental history of atopy

Background Diet: 77\% ever BF; $73 \%$ BF <6mo; $40 \%$ introduced to CFB $<4 \mathrm{mo}$

\begin{tabular}{ll}
\hline Kajosaari, 1983 & Intervention/Exposure: \\
Prospective Cohort Study; Finland & Age of CFB introduction: $\sim 3,6 \mathrm{mo}$ \\
& Assessment Methods: NR
\end{tabular}

Sample Size:

Baseline N: 135

Outcomes:
Intervention/Exposure:

Age of CFB introduction: $<4,>4$ mo

Assessment Methods: Parent interview

Outcomes:

Atopic dermatitis

Age: 2-3y

Assessment Methods:

Atopic dermatitis: NR

\section{Confounders, Limitations}

done for other outcomes reported in the study (food

allergen sensitization, asthma, wheeze)

\section{Confounders:}

The following confounders were accounted for: Education; SES; Sex; Race/ethnicity; Feeding practices; Smoking; Atopy risk status; Birth order; Marital status

\section{Limitations:}

Cannot determine whether participants were similar at baseline on key characteristics of gestational age or birth weight

Cannot determine whether outcome assessors were blinded

Validity/Reliability of measures used not clear

Did not adjust for key confounders (birth size, gestational age)

Asthma defined as early childhood wheezing
Assessment Methods: NR

Confounders:

No confounders were adjusted for

Limitations:

Outcome assessors were not blinded 


\section{References; Subject Characteristics (Sample Size, Sex, Race/Ethnicity, Atopic Disease Risk Status; Background Diet)}

\section{Analytic N: 135}

Attrition: N/A

Sample Size Calculation: NR

Sex: NR

Race/Ethnicity: NR

Atopic Disease Risk Status: $100 \%$ had familial risk (either parent either asthma or allergy)

Background Diet: EBF to 6mo: 52\%; no infants received formula

Age of CFB introduction: $48 \%$ by $3 \mathrm{mo}$

Kajosaari, 1994

Prospective Cohort Study; Finland

\section{Sample Size:}

Baseline N: 135

Analytic N: 135

Attrition: N/A

Sample Size Calculation: NR

Sex: NR

Race/Ethnicity: NR

Atopic Disease Risk Status: $100 \%$ had familial risk (either parent either asthma or allergy)

Background Diet: EBF to 6mo: 52\%; no infants received formula

Age of CFB introduction: $48 \%$ by $3 \mathrm{mo}$

\section{Independent Variable/Exposure, Outcomes}

\section{Food allergy, eczema}

Age: $1 \mathrm{y}$

Assessment Methods:

Food allergy: History of skin rash or vomiting after ingestion, confirmed by elimination diet and home challenges

Eczema: Parent report of physician diagnosis of eczema, and/or diagnosis by study personnel

\section{Confounders, Limitations}

Cannot determine whether participants were similar on any baseline characteristics

Did not adjust for key confounders (education, SES, sex, race/ethnicity, feeding practices, birth size, gestational age, smoking, atopy risk status)

Did not use valid/reliable measures for outcome measure for food allergy

Limited generalizability due to exclusive enrollment of high risk infants

\section{Intervention/Exposure:}

Age of CFB introduction: $\sim 3,6 \mathrm{mo}$

Assessment Methods: NR

\section{Outcomes:}

Food allergy, atopic eczema, asthma, allergic rhinitis, atopic disease

Age: $5 y$

Assessment Methods:

Food allergy: Parent report of repeated skin rash, urticaria or heavy vomiting after ingestion

Atopic eczema: Examination by study personnel Asthma: Parent reported asthma diagnosis

Allergic rhinitis: History of seasonal symptoms (nasal discharge, itching conjunctivities, wheezing)
Confounders:

No confounders were adjusted for

Limitations:

Outcome assessors were not blinded

Cannot determine whether participants were similar on any baseline characteristics

Did not adjust for key confounders (education, SES, sex, race/ethnicity, feeding practices, birth size, gestational age, smoking, atopy risk status)

Did not use valid/reliable measures to assess outcomes, especially food allergy Limited generalizability due to exclusive enrollment of high risk infants

Small sample size; study may have been underpowered 


\section{References; Subject Characteristics (Sample Size, Sex, Race/Ethnicity, Atopic Disease Risk Status; Background Diet)}

\section{Independent Variable/Exposure, Outcomes}

contacts

Atopic disease: Atopic eczema, asthma, or positive SPT corresponding with history of food, pollen, or animal dander (birth, alm, timothy, mugwort dog \& cat epithelium, fish, milk, \& wheat

\section{Luccioli, 2014}

Prospective Cohort Study; United States (Infant Feeding Practices Study II Year 6 Follow-Up Study)

\section{Sample Size:}

Baseline N: 1531

Analytic N: 1363

Attrition: $12 \%$

Sample Size Calculation: NR

Sex: 51\% Female

Race/Ethnicity: 86\% White Non-Hispanic; 2\%

Asian Non-Hispanic; 4\% Black Non-Hispanic; 6\%

Hispanic; 2\% Other

Atopic Disease Risk Status: 23\% had parent

history of food allergy; $44 \%$ had parent history of atopy

Background Diet: $43 \%$ EBF at 0 mo, 30\% at 1-

$3 \mathrm{mo}, 27 \%$ at $4 \mathrm{mo}+$; Introduced to CFB: $34 \%$ at $1-$ $3 \mathrm{mo} ; 40 \%$ at $4-5 \mathrm{mo} ; 17 \%$ at $6-12 \mathrm{mo} ; 9 \% \mathrm{NR}$

Intervention/Exposure:

Age of CFB introduction: 1-3/<4, 4-5, 6-12mo, NR

Assessment Methods: Maternal questionnaire

Outcomes:

Food allergy

Age: 6y

Assessment Methods:

Food allergy: Maternal report of physician diagnosis
Confounders, Limitations gestational age) Outcome measures used were not valid/reliable Did not adjust for key confounders (birth size,

\section{Confounders:}

The following confounders were accounted for: Education; SES; Sex; Race/ethnicity; Feeding practices; Smoking; Atopy risk status; Delivery mode; Parity

\section{Limitations:}

Cannot determine whether groups were similar at baseline on key characteristics

Outcome assessors were not blinded

\begin{tabular}{ll}
\hline McGowan, 2015 & Intervention/Exposure: \\
Prospective Cohort Study; United States & Age of CFB introduction: Age in wk, continuous
\end{tabular}




\section{References; Subject Characteristics (Sample Size, Sex, Race/Ethnicity, Atopic Disease Risk Status; Background Diet)}

(Urban Environment and Childhood Asthma) (URECA)

Sample Size:

Baseline N: 609

Analytic N: 516

Attrition: $15 \%$

Sample Size Calculation: NR

Sex: 56\% Female

Race/Ethnicity: 61\% Black, 16\% Hispanic, 7\% Other

Atopic Disease Risk Status: 80\% had parental history of allergic rhinitis, eczema, or asthma

Background Diet: 44\% ever BF, 18\% BF at 3mo; CFB introduced at $15 \mathrm{wk}(\mathrm{SD}=\sim 8.5 \mathrm{wk})$

\section{Mihrshahi, 2007}

Prospective Cohort Study; Australia

(Childhood Asthma Prevention Study)

\section{Sample Size:}

Baseline N: 616

Analytic N: 516

Attrition: $16 \%$

Sample Size Calculation: NR

\section{Independent Variable/Exposure, Outcomes}

Assessment Methods: Maternal interview

Outcomes:

Food allergy

Age: $5 y$

Assessment Methods:

Food allergy: Positive IgE level (>0.35 kU/L) to milk, egg, and/or peanut, avoidance of sensitized foods, and clinical confirmation (parent report of previous food reaction to milk, egg or peanut; or classified as FA by allergist consult)

\section{Confounders, Limitations}

The following confounders were accounted for: Sex;

Gestational age; Atopy risk status; Site

\section{Limitations:}

Cannot determine whether groups were similar at baseline on key characteristics

Limited information provided about CFB assessment

Did not use valid/reliable measures to diagnose food allergy

Cannot determine whether outcome assessors were blinded

Did not adjust for key confounders (education, SES, race/ ethnicity, feeding practices, birth size, smoking)

Generalizability limited to inner-city children in small number of US cities with parental history of allergy/asthma

Large number of subjects classified as "possibly allergic" and weren't included in analyses

\section{Confounders:}

The following confounders were accounted for: Education; Sex; Feeding practices; Birth size; Gestational age; Smoking; Atopy risk status; Intervention group

Outcomes:

Eczema, asthma

Age: $5 y$

Assessment Methods:

\section{Limitations:}

Cannot determine whether groups were similar at baseline on key characteristics 
References; Subject Characteristics (Sample Size, Sex, Race/Ethnicity, Atopic Disease Risk Status; Background Diet)

\section{Sex: NR}

Race/Ethnicity: NR

Atopic Disease Risk Status: 100\% had one or more parents or siblings had asthma or wheezing

Background Diet: 90\% ever BF, 34\% EBF at 3mo, $2 \%$ EBF at $6 \mathrm{mo}$; CFB introduced by $26 \%$ at $3 \mathrm{mo}$

Nathan, 2012
Case-Control Study; Malaysia
Sample Size:
Asthma Cases: 78
Controls: 78
Attrition: NA
Sample Size Calculation: NR
Sex: $46 \%$ Female
Race/Ethnicity: $65 \%$ Malay, 13\% Chinese, 22\%
Indian

Atopic Disease Risk Status: $77 \%$ cases vs $21 \%$ controls had family history of atopy, $80 \%$ vs $21 \%$ had family history of asthma

Background Diet: $28 \%$ were EBF >6mo

\section{Independent Variable/Exposure, Outcomes}

Eczema: Presence of flexural eczema, or a history

of itchy rash coming and going for $>3 \mathrm{mo}$, and at

least one of the following: seeking medical care for

diagnosed eczema/atopic dermatitis or using steroid

or emollient creams in the last $12 \mathrm{mo}$

Asthma (probable current): Any wheeze in last

$12 \mathrm{mo}$ in children who either had asthma diagnosed

by a doctor or at a hospital, or a positive

bronchodilator test

Intervention/Exposure:

Age of CFB introduction: <6, >6mo

Assessment Methods: Parent questionnaire

Outcomes:

Asthma

Age: 3-15y

Assessment Methods:

Asthma: Recurrent episodes of doctor-diagnosed wheezing with use of acute reliever and/or inhaler medication
Did not use valid/reliable measures to assess all outcomes (asthma)

Did not adjust for key confounders (SES, race/ethnicity)

Generalizability limited to those with a family history of asthma

\section{Confounders, Limitations}


References; Subject Characteristics (Sample Size, Sex, Race/Ethnicity, Atopic Disease Risk

Status; Background Diet)

Sample Size:

Baseline N: 1,537

Analytic N: 709

Attrition: $54 \%$

Sample Size Calculation: NR

Sex: $48 \%$ Female

Race/Ethnicity: NR

Atopic Disease Risk Status: 43\% had maternal family history or atopy, $34 \%$ had parental family history of atopy

Background Diet: $14 \% \mathrm{EBF}$ at $2 \mathrm{mo} ; 22 \% \mathrm{BF}$ at $6 \mathrm{mo} ; 19 \%$ introduced to CFB by $17 \mathrm{wk}, 6 \%$ introduced $>26 \mathrm{wk}$

\section{Poysa, 1989 \\ Prospective Cohort Study; Finland}

Sample Size:

Baseline N: 100

Analytic N: 70

Attrition: $30 \%$

Sample Size Calculation: NR

Sex: NR

Race/Ethnicity: NR

Atopic Disease Risk Status: All subjects had family atopy history
Independent Variable/Exposure, Outcomes

Outcomes:

Atopic dermatitis

Age: $12 \mathrm{mo}$

Assessment Methods:

Atopic dermatitis: Parent report, with formal diagnosis using UK Working Party Diagnostic Criteria

Intervention/Exposure:

Age of CFB introduction: $<3,3-6$, $>6 \mathrm{mo}$ (CFB: avoided "classic dietary allergens" until $9 \mathrm{mo}$ )

Assessment Methods: Parent questionnaire

Outcomes:

Atopic dermatitis

Age: $5 y$

Assessment Methods:

Atopic dermatitis: Diagnosis by a dermatologist; pruritic dermatitis accompanied by dry skin on the face in infancy and on flexural surfaces of the extremities later

\section{Confounders, Limitations}

vitamin $D$ status, season of birth, rural/urban, maternal alcohol and vit D intake at 15wk, C-section, marital status, maternal BMI, maternal age

\section{Limitations:}

Cannot determine whether groups were similar at baseline on key characteristics

Outcome assessors were not blinded

Did not adjust for key confounders (SES, race/ethnicity, gestational age)

Did not assess the impact of high loss to follow-up ( $>50 \%$ by $12 \mathrm{mo}$ )

\section{Confounders:}

No confounders were adjusted for

\section{Limitations:}

Cannot determine whether groups were similar at baseline on key characteristics

Did not adjust for key confounders (SES, sex, education, race/ethnicity, birth size, gestational age, feeding practices, atopy risk status, smoking)

Did not account for high loss to follow-up ( $30 \%)$

Did not report statistical results of analyses

Limited generalizability due to exclusive enrollment of high risk infants 


\begin{abstract}
References; Subject Characteristics (Sample
Size, Sex, Race/Ethnicity, Atopic Disease Risk

Status; Background Diet)
\end{abstract}

Independent Variable/Exposure, Outcomes

Confounders, Limitations

Background Diet: Subjects with atopy history

advised to $\mathrm{BF}$ for $>3 \mathrm{mo}$, to not introduce formula

or cow's milk before $3 \mathrm{mo}$, and to avoid the "classic

dietary allergens until 9mo; $52 \%$ followed this diet

BF: $24 \%<3 \mathrm{mo}, 14 \%$ 3-6mo, 61\% >6mo; FF: 36\%

$<3 \mathrm{mo}, 30 \%$ 3-6mo, 44\% >6mo; CFB: $23 \%<3 \mathrm{mo}$,

$73 \%$ 3-6mo, 4\% >6mo

\section{Poysa, 1991}

Prospective Cohort Study; Finland

Sample Size:

Baseline N: 100

Analytic N: 68

Attrition: $32 \%$

Sample Size Calculation: NR

Sex: NR

Race/Ethnicity: NR

Atopic Disease Risk Status: 100\% had family history of atopy

Background Diet: Subjects with atopy history advised to BF for $>3 \mathrm{mo}$, to not introduce formula or cow's milk before $3 \mathrm{mo}$, and to avoid the "classic dietary allergens until 9mo; $52 \%$ followed this diet

BF: $24 \%<3 \mathrm{mo}, 14 \%$ 3-6mo, 61\% >6mo; FF: 36\% $<3 \mathrm{mo}, 30 \%$ 3-6mo, 44\% >6mo; CFB: $23 \%<3 \mathrm{mo}$, $73 \%$ 3-6mo, $4 \%>6 \mathrm{mo}$

\section{Intervention/Exposure:}

Age of CFB introduction: $<3,3-6,>6 \mathrm{mo}$

Assessment Methods: Parental questionnaire

Outcomes:

Atopy

Age: $9 y$

Assessment Methods:

Atopy: Parent report of physician diagnosis of asthma, allergic rhinitis, allergic conjunctivitis, atopic dermatitis (diagnosis made by dermatologist), and/or food allergy; allergies to fruit and or apple tested at home (elimination diet) and allergies to eggs or fish confirmed by hospital challenge)

\section{Confounders:}

No confounders were adjusted for

\section{Limitations:}

Cannot determine whether groups were similar at baseline on key characteristics

Did not account for high loss to follow-up ( $30 \%)$

Did not use valid/reliable measures to measure outcomes

Did not adjust for key confounders (SES, sex, education, race/ethnicity, birth size, gestational age, feeding practices, atopy risk status, smoking)

Sandini, 2011 
References; Subject Characteristics (Sample Size, Sex, Race/Ethnicity, Atopic Disease Risk

Status; Background Diet)

\section{Sample Size:}

Baseline N: 1223

Analytic N: 925 at 2y, 891 at 5y

Attrition: $24 \%$ at $2 y, 27 \%$ at $5 y$

Sample Size Calculation: Yes, but based on RCT of probiotics for allergy prevention conducted in this same population

\section{Sex: 50\% Female}

Race/Ethnicity: NR

Atopic Disease Risk Status: 100\% had at least one parent with an allergic disease

Background Diet: 45\% EBF for 2-4mo, 61\% BF $>6 \mathrm{mo}$, solids started at $\sim 4 \mathrm{mo}(\mathrm{SD}=0.7)$, with $67 \%$ $\geq 4 \mathrm{mo}$

\section{Independent Variable/Exposure, Outcomes}

Assessment Methods: Parent questionnaire

Outcomes:

Food allergy, eczema, asthma, allergic rhinitis

Age: $2 y, 5 y$

Assessment Methods:

Food allergy: OFC in infants whose food-related symptoms (urticaria, eczema, vomiting, loose stools, abdominal pain, and excessive crying) improved during a 2wk elimination diet

Eczema: Itchy skin plus all or 3 of the following: history of atopic disease in the family, dry skin during the last year, history of eczema, or visible eczema involving typical sites

Asthma: 2+ physician-diagnosed wheezing episodes with persistent cough or as exerciseinduced (including giggling and crying) symptoms; verified by the study pediatrician review of patient records

Allergic rhinitis: Allergen-specific sensitization with a history of 2 or more symptoms (nasal discharge, blockage, or sneezing/itching) recurrently during antigen contact

\section{Schoetzau, 2002}

Prospective Cohort Study; Germany(German Infant Nutritional Intervention Program)

Sample Size:

Baseline N: 2252

\section{Intervention/Exposure:}

Age of CFB introduction: 1-16, 17-24, >24wk

Assessment Methods: Food diary

\section{Confounders, Limitations}

The following confounders were accounted for: Sex; Feeding practices; Gestational age; Smoking; Atopy risk status; Delivery mode, siblings, antibiotic use, airway infections, dog/cat exposure; RCT study group

Limitations:

Cannot determine whether groups were similar at baseline on key characteristics

Did not adjust for key confounders (SES, race/ethnicity birth size)

Outcome assessors were not blinded

Did not define age of CFB introduction

Limited generalizability due to exclusive enrollment of high risk infants

\section{Confounders:}

The following confounders were accounted for: Education; Sex; Race/ethnicity; Feeding practices; Gestational age; Smoking; Atopy risk status; Pets 
References; Subject Characteristics (Sample Size, Sex, Race/Ethnicity, Atopic Disease Risk Status; Background Diet)

\section{Analytic N: 1121}

Attrition: 50\%

Sample Size Calculation: NR

Sex: $49 \%$ Female

\section{Race/Ethnicity: NR}

Atopic Disease Risk Status: $42 \%$ had 1+ core family members with atopic dermatitis; all infants had extended family members with some atopic disease

Background Diet: 23\% formula fed, 77\% BF

\section{Snijders, 2008}

Prospective Cohort Study; The Netherlands (KOALA Birth Cohort Study)

Sample Size:

Baseline N: 2834

Analytic N: 2558

Attrition: $10 \%$

Sample Size Calculation: NR

Sex: 49\% Female

Race/Ethnicity: NR

Atopic Disease Risk Status: 60\% had parental allergic disease, $19 \%$ had sibling allergic disease

Background Diet: 15\% never BF, 33\% BF 0-3mo, $17 \%$ BF 4-6mo, 15\% BF 7-9mo, 17\% BF >9mo; $39 \%$ introduced to cow milk products by $3 \mathrm{mo}$; $89 \%$ introduced to other solid foods from 4-6mo

\section{Independent Variable/Exposure, Outcomes}

Atopic dermatitis

Age: 1y

Assessment Methods:

Atopic dermatitis: Physician diagnosis defined by a combination of diagnostic criteria, including typical morphology and distribution of skin lesions (face, neck and scalp, flexural folds, hands and extensor sides of extremities); pruritus (signs of scratching); and a tendency towards chronicity (duration of least 14d and/or relapsing)

\section{Intervention/Exposure:}

Age of CFB introduction: <3, 4-6, >7mo

Assessment Methods: Parent questionnaire

Outcomes:

Eczema/atopic dermatitis

Age: $2 \mathrm{y}$

Assessment Methods:

Eczema: Parent report of itchy rash

Atopic dermatitis: Parent report of the presence of itchy rash, history of flexural dermatitis,, presence of visible flexural dermatitis, and onset before 2y; UK AD scoring system with home visit and visualization of skin at 2y)

\section{Confounders, Limitations}

Cannot determine whether groups were similar at baseline on key characteristics

Did not account for high loss to follow-up (>50\% by 1y)

Did not adjust for key confounders (SES, birth size)

\section{Confounders:}

The following confounders were accounted for: Education; Sex; Feeding practices; Smoking; Atopy risk status; Conventional/ alternative lifestyle; Maternal age at delivery

\section{Limitations:}

Cannot determine whether groups were similar at baseline on key characteristics

Outcome assessors were not blinded

Did not use valid/reliable measures (parent reported outcomes)

Did not adjust for key confounders (SES, race/ethnicity, birth size, gestational age) 


\section{References; Subject Characteristics (Sample Size, Sex, Race/Ethnicity, Atopic Disease Risk Status; Background Diet)}

Taylor-Robinson, 2016
Prospective Cohort Study; United Kingdom (UK
Millennium Cohort Study)

Sample Size:

Baseline N: 14499

Analytic N: 11537

Attrition: $20 \%$

Sample Size Calculation: NR

Sex: $49 \%$ Female

Race/Ethnicity: 88\% White, 3\% Mixed, 2\% Indian, 4\% Pakistani/ Bangladeshi, 3\% Black

Atopic Disease Risk Status: $23 \%$ of mothers had asthma or eczema

Background Diet: 31\% never BF, 27\% BF >6mo; $55 \%$ introduced to cow's milk $<9$ mo

Van Asperen, 1984

Prospective Cohort Study; Australia

Sample Size:

Baseline N: NR

Analytic N: 79

Attrition: Cannot determine

Sample Size Calculation: NR

Sex: NR

\section{Intervention/Exposure:}

Age of CFB introduction: $<4,>4 \mathrm{mo}$

Assessment Methods: Parent questionnaire (ISAAC)

Independent Variable/Exposure, Outcomes

Outcomes:

Eczema

Age: $5 y$

Assessment Methods:

Eczema: Parent report of whether their child had 'ever had eczema'
Confounders, Limitations

\section{Confounders:}

The following confounders were accounted for: Education; Sex; Race/ethnicity; Feeding practices; Birth size; Gestational age; Smoking; Atopy risk status; Maternal age, maternal BMI, C-section, antibiotic use, dampness at home, exposure to pollution and "grime", furry pets, siblings

\section{Limitations:}

Cannot determine whether groups were similar at baseline on key characteristics

Outcome assessors were not blinded

Did not use valid/reliable measures (parent reported outcomes)

Did not adjust for key confounders (SES)
Intervention/Exposure:

Age of CFB introduction: $<4,>4 \mathrm{mo}$

Assessment Methods: Parent interview

Outcomes:

Atopic dermatitis, allergic rhinitis

Age: $20 \mathrm{mo}$

Assessment Methods:

Atopic dermatitis: Parent report of evidence of areas of scaly, erythematous, pruritic dermatitis primarily

\section{Confounders:}

No confounders were adjusted for

\section{Limitations:}

Cannot determine whether groups were similar at baseline on key characteristics

Cannot determine whether outcome assessors were blinded

Did not use valid/reliable measures (to assess outcomes) 


\section{References; Subject Characteristics (Sample Size, Sex, Race/Ethnicity, Atopic Disease Risk Status; Background Diet)}

\section{Race/Ethnicity: NR}

Atopic Disease Risk Status: 100\% had family history (parent or sibling) of atopic disease

Background Diet: 25\% EBF at $4 \mathrm{mo}$

\section{Independent Variable/Exposure, Outcomes}

involving flexural folds, face, cheeks or areas behind the ears but excluding xeroderma alone

Allergic rhinitis: Parent report of history of nasal discharge and/or blockage occurring continuously for at least 4wk and excluding obvious infective rhinitis

\section{Confounders, Limitations}

Did not adjust for any key confounders (Education,

SES, sex, race/ethnicity, feeding practices, birth size, gestational age, smoking, atopy risk status)

Limited generalizability due to exclusive enrollment of high risk subjects

Small sample size; study may have been underpowered

\section{Venter, 2009}

Prospective Cohort Study; United Kingdom

\section{Sample Size:}

Baseline N: 969

Analytic N: 927 at 3mo, 913 at $6 \mathrm{mo}, 900$ at 9 and $12 \mathrm{mo}, 858$ at $24 \mathrm{mo}$

Attrition: $4 \%$ at $3 \mathrm{mo}, 6 \%$ at $6 \mathrm{mo}, 7 \%$ at 9 and $12 \mathrm{mo}, 12 \%$ at $24 \mathrm{mo}$

Sample Size Calculation: NR

Sex: $48 \%$ Female

Race/Ethnicity: NR

Atopic Disease Risk Status: 83\% had family history of allergic disease

Background Diet: BF duration: 42d, formula introduced $\sim 14 \mathrm{~d}$; $27 \%$ introduced CFB $<3 \mathrm{mo}, 82 \%$ $<4 \mathrm{mo}, 100 \%$ by $6 \mathrm{mo}$
Intervention/Exposure:

Age of CFB introduction: $<4,>4 \mathrm{mo}$

Assessment Methods: Parental questionnaire

Outcomes:

Food allergy

Age: 1y, 3y

Assessment Methods:

Food allergy: Parent report of symptoms, SPT wheal >3mm (milk, egg, wheat, cod, peanut, sesame), and DBPCFC

\section{Confounders:}

No confounders were adjusted for

\section{Limitations:}

Cannot determine whether groups were similar at baseline on key characteristics

Cannot determine whether outcome assessors were blinded

Did not adjust for any key confounders (Education, SES, sex, race/ethnicity, feeding practices, birth size, gestational age, smoking, atopy risk status)Small number of subjects diagnosed with food allergy; study may have been underpowered
Wilson, 1998

Prospective Cohort Study; Australia
Intervention/Exposure:

Age of CFB introduction: $<15,>15 w k$
Confounders:

The following confounders were accounted for: SES; Sex; Feeding practices; Birth size; Gestational age; 
References; Subject Characteristics (Sample Size, Sex, Race/Ethnicity, Atopic Disease Risk

Status; Background Diet)

\section{Sample Size:}

Baseline N: 674

Analytic N: 545

Attrition: $19 \%$

Sample Size Calculation: NR

Sex: 54\% Female

Race/Ethnicity: NR

Atopic Disease Risk Status: $25 \%$ had paternal history of allergic disease, $27 \%$ had maternal history of allergic disease

Background Diet: $26 \%$ EBF at 15wk, 37\% partial $\mathrm{BF}$ at $15 \mathrm{wk}, 37 \%$ formula fed at $15 \mathrm{wk} ; 73 \%$ introduced to CFB $<15 \mathrm{wk}$

\section{Yung, 2015 \\ Case-Control Study; China (Hong Kong)}

\section{Sample Size:}

Cases: 71

Controls: 135

Attrition: NA

Sample Size Calculation: NR

Sex: 46\% Female

Race/Ethnicity: NR

Atopic Disease Risk Status: $44 \%$ had parental history of atopic disease

\section{Independent Variable/Exposure, Outcomes}

Assessment Methods: Parent questionnaire

Outcomes:

Asthma

Age: -7.3y (6.1-9.9y)

Assessment Methods:

Asthma: Parent report of doctor diagnosis at any time since birth (ever) or if the child was currently receiving asthma treatment (current)

\section{Confounders, Limitations}

Smoking; Atopy risk status; Weight at first solid feed; Maternal height; Maternal blood pressure; Parity

Limitations:

Cannot determine whether groups were similar at baseline on key characteristics

Outcome assessors were not blinded

Did not use valid/reliable measures (to assess outcomes)

Did not adjust for any key confounders (Education, race/ethnicity)
Intervention/Exposure:

Age of CFB introduction: Age in wks, continuous Assessment Methods: Maternal questionnaire

Outcomes:

Atopic disease

Age: $21 \mathrm{mo}$ (SD: 11mo) (range: 4mo-3y)

Assessment Methods:

Atopy: Physician-diagnosed atopy (eczema or allergic dermatitis, asthma, rhinitis, conjunctivitis (not related to infection), and allergies (dust mite, food, drug, etc.); diagnostic methods and criteria not described
Confounders:

No confounders were adjusted for

Limitations:

Cannot determine whether groups were similar at baseline on key characteristics

Did not adjust for any key confounders (Education, SES, sex, race/ethnicity, feeding practices, birth size, gestational age, smoking, atopy risk status)

Cannot determine whether valid/reliable measures were used to assess outcomes 


\section{References; Subject Characteristics (Sample Size, Sex, Race/Ethnicity, Atopic Disease Risk Status; Background Diet)}

Background Diet: 75\% EBF at birth, 64\% EBF at $3 \mathrm{mo}, 27 \%$ EBF at $6 \mathrm{mo}$; age when solid food was introduced $\sim 25 \mathrm{wk}$

\section{Zutavern, 2006}

Prospective Cohort Study; Germany (LifestyleRelated Factors on the Immune System and the Development of Allergies in Childhood)

Sample Size:

Baseline N: 3097

Analytic N: 2612

Attrition: $16 \%$

Sample Size Calculation: NR

Sex: 48\% Female

Race/Ethnicity: NR

Atopic Disease Risk Status: 53\% with parental history of atopy

Background Diet: 59\% EBF 4 mo, 35.7\% mixed fed, $5.2 \%$ formula fed

\section{Independent Variable/Exposure, Outcomes}

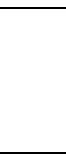

Intervention/Exposure:

\author{
Age of CFB introduction: 0-4, 5-6, >6mo
}

Assessment Methods: Parent questionnaire

\section{Outcomes:}

Atopic dermatitis

Age: $2 y$

Assessment Methods:

Doctor-diagnosed atopic dermatitis: Parent report of physician diagnosis of $A D$ in the last $6 \mathrm{mo}$

Symptomatic atopic dermatitis: Parent report of itching eczema within the last 6 mo that was either recurrent or lasted for $2 \mathrm{wk}$ and that affected the skin creases, face, neck, extremities, hands, feet, or trunk (not underneath the diaper)

Early skin or allergic symptoms: Parent affirmative response to, "Has a doctor diagnosed your child with 1 of the following conditions within the first $6 \mathrm{mo}$ of life: atopic dermatitis; allergic or atopic eczema; food allergy, hives, urticaria, or allergic edema; milk crust or seborrheic eczema; eczema without further specification?" or when parents reported an increase of eczema as a result of food intolerance within the first $6 \mathrm{mo}$ of their child's life

\section{Zutavern, 2008}

\section{Intervention/Exposure:}

Age of CFB introduction: $<4,4-6,>6$ mo

\section{Confounders, Limitations}

Retrospective nature of dietary recall to determine age of introduction to solid foodsSmall sample size; study may have been underpowered

\section{Confounders:}

The following confounders were accounted for:

Education; Sex; Feeding practices; Birth size; Smoking Atopy risk status; Study center; Number of siblings

\section{Limitations:}

Cannot determine whether groups were similar at baseline on key characteristics

Outcome assessors were not blinded

Did not use valid/reliable measures to assess outcomes (parent report)

Did not adjust for any key confounders (SES, race/ethnicity, gestational age, pets)

\section{Confounders:}

The following confounders were accounted for: Education; Sex; Feeding practices; Smoking; Atopy risk 


\section{References; Subject Characteristics (Sample Size, Sex, Race/Ethnicity, Atopic Disease Risk Status; Background Diet)}

Prospective Cohort Study; Germany (LifestyleRelated Factors on the Immune System and the

Development of Allergies in Childhood)

Sample Size:

Baseline N: 3097

Analytic N: 2073

Attrition: $33 \%$

Sample Size Calculation: NR

Sex: $49 \%$ Female

Race/Ethnicity: NR

Atopic Disease Risk Status: 53\% with parental history of atopy

Background Diet: 59\% EBF at 4mo, 35.7\% mixed fed, $5.2 \%$ formula fed

\section{Independent Variable/Exposure, Outcomes}

Assessment Methods: Parent questionnaire

Outcomes:

Eczema, asthma, allergic rhinitis

Age: $6 y$

Assessment Methods:

Atopic dermatitis: Parent report of physician diagnosis, or itching eczema within the last $6 \mathrm{mo}$ that was either recurrent or lasted for $2 \mathrm{wk}$ and that affected the skin creases, face, neck, extremities, hands, feet, or trunk (not underneath the diaper)

Asthma: Parent report of physician diagnosis of asthma or report of wheezing or intake of asthma medication

Allergic rhinitis: Parent report of physician diagnosis of allergic rhinitis, or report of sneezing or a blocked

or running nose without having a cold

\section{Confounders, Limitations}

status; Study center, number of siblings; Maternal age at birth

\section{Limitations:}

Cannot determine whether groups were similar at baseline on key characteristics

Outcome assessors were not blinded

Did not use valid/reliable measures to assess outcomes (parent report)

Did not adjust for any key confounders (SES, race/ethnicity, gestational age, birth size, pets) 
Table 2. Results from studies that examined the relationship between age of first introduction of any complementary foods and/or beverages (CFB) and food allergy, atopic dermatitis, asthma, and allergic rhinitis.

\begin{tabular}{|c|c|c|}
\hline $\begin{array}{l}\text { Reference }{ }^{1} \text {; Study design; Country; Sample } \\
\text { size }\end{array}$ & Age of CFB introduction & Results \\
\hline \multicolumn{3}{|l|}{ FOOD ALLERGY } \\
\hline \multirow{2}{*}{$\begin{array}{l}\text { Grimshaw, } 2013 \text { (9); Nested Case-Control } \\
\text { Study (Prevalence of Infant Food Allergy } \\
\text { EuroPrevall); United Kingdom; Food Allergy } \\
\text { Cases: 41, Controls: } 82\end{array}$} & Age in weeks, mean & Food allergy cases vs. controls: $18 w k$ vs $20 w k ; P=0.044$ \\
\hline & $>17 w k$ vs. $<17 w k$ & Food allergy at 2y: OR=0.245; 95\% Cl: 0.088, 0.679; $\mathrm{P}<0.05$ \\
\hline \multirow{3}{*}{$\begin{array}{l}\text { Grimshaw, } 2015 \text { (8); Nested Case-Control } \\
\text { Study (Prevalence of Infant Food Allergy } \\
\text { EuroPrevall); United Kingdom; Food Allergy } \\
\text { Cases: 41, Controls: } 82\end{array}$} & Age in weeks, cases vs. controls & Food allergy at 2y: OR=0.506, 95\% Cl: $0.282,0.908 ; \mathrm{P}=0.022$ \\
\hline & & Food allergy, non-IgE-mediated at $2 \mathrm{y}: \mathrm{OR}=0.60,95 \% \mathrm{Cl}: 0.40,0.89 ; \mathrm{P}=0.011$ \\
\hline & & Food allergy, IgE-mediated, at 2y: No significant associations \\
\hline $\begin{array}{l}\text { Hesselmar, } 2010 \text { (1); Prospective Cohort } \\
\text { Study (ALLERGY-FLORA); Sweden; N: } 184\end{array}$ & Age in months, continuous & Food allergy at 18mo: No significant associations \\
\hline $\begin{array}{l}\text { Kajosaari, } 1983 \text { (2); Prospective Cohort } \\
\text { Study; Finland; N: } 135\end{array}$ & $\sim 3$ vs. $6 \mathrm{mo}$ & Food allergy at $1 \mathrm{y}: 37 \%$ vs.7\%; $\mathrm{P}<0.001$ \\
\hline $\begin{array}{l}\text { Kajosaari, } 1994 \text { (3); Prospective Cohort } \\
\text { Study; Finland; N: } 135\end{array}$ & $\sim 3$ vs. $6 \mathrm{mo}$ & Food allergy at 5y: No significant associations \\
\hline $\begin{array}{l}\text { Luccioli, } 2014 \text { (4); Prospective Cohort Study; } \\
\text { United States (Infant Feeding Practices Study } \\
\text { II Year } 6 \text { Follow-Up Study); N: } 1363\end{array}$ & $1-3 /<4$ vs. $4-5$ vs. $6-12 \mathrm{mo}$ & Food allergy at 6y: No significant associations \\
\hline $\begin{array}{l}\text { McGowan, } 2015 \text { (5); Prospective Cohort } \\
\text { Study (Urban Environment and Childhood } \\
\text { Asthma Cohort); United States; N: } 516\end{array}$ & Categories not defined & Food allergy at 5y: No significant associations \\
\hline $\begin{array}{l}\text { Sandini, } 2011 \text { (6); Prospective Cohort Study; } \\
\text { Finland; N: } 925 \text { at 2y, } 891 \text { at 5y }\end{array}$ & Categories not defined & Food allergy at 2y and 5y: No significant associations \\
\hline
\end{tabular}




\section{Reference ${ }^{1}$; Study design; Country; Sample Age of CFB introduction}

size

Venter, 2009 (7); Prospective Cohort Study;

United Kingdom; N: 927 at 3mo, 913 at 6mo,

900 at 9 and $12 \mathrm{mo}, 858$ at $24 \mathrm{mo}$

$<4$ vs. $>4 \mathrm{mo}$

\section{Results}

Food allergy at 1y: OR=0.41, 95\% $\mathrm{Cl} 0.18,0.89 ; P=0.02$

Food allergy at 3y: OR=0.51, 95\% Cl: 0.28, 0.92; $P=0.02$

\section{ATOPIC DERMATITIS}

Chuang, 2011 (10); Prospective Cohort Study; <4, 4-6, >6mo

Taiwan; N: 18733

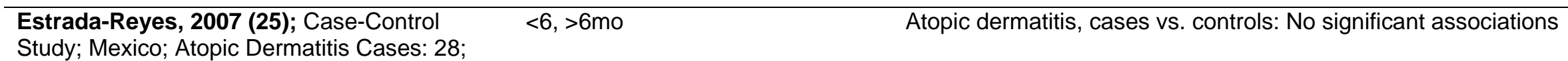

Controls: 28

Fergusson, 1981 (11); Prospective Cohort $\quad<4,>4 m o \quad$ Atopic dermatitis at 2y: 17.78\% vs. 12.58\%; P<0.05

Study; New Zealand; N: 1156

Filipiak, 2007 (12); Prospective Cohort Study; 1-4, 5-6, 7-12mo Germany; N: 4753

Forsyth, 1993 (13); Prospective Cohort Study; $<8,8-12,>12$ wk

Scotland; N: 392

\begin{tabular}{|c|c|c|}
\hline $\begin{array}{l}\text { Hesselmar, } 2010 \text { (1); Prospective Cohort } \\
\text { Study; Sweden; N: } 184\end{array}$ & Age in months, continuous & Atopic dermatitis at 18mo: No significant associations \\
\hline $\begin{array}{l}\text { Illi, } 2004 \text { (14); Prospective Cohort Study; } \\
\text { Germany; N: } 858\end{array}$ & Quartiles (not described) & Atopic dermatitis at 2y: No significant associations \\
\hline $\begin{array}{l}\text { Joseph, } 2011 \text { (15); Prospective Cohort Study; } \\
\text { United States; N: } 594\end{array}$ & $<4,>4 \mathrm{mo}$ & Atopic dermatitis at 2-3y: No significant associations \\
\hline $\begin{array}{l}\text { Kajosaari, } 1983 \text { (2); Prospective Cohort } \\
\text { Study; Finland; N: } 135\end{array}$ & $\sim 3,6 \mathrm{mo}$ & Atopic dermatitis at 1y: 35\% vs.14\%; P<0.001 \\
\hline $\begin{array}{l}\text { Kajosaari, } 1994 \text { (3); Prospective Cohort } \\
\text { Study; Finland; N: } 135\end{array}$ & $\sim 3,6 \mathrm{mo}$ & Atopic dermatitis at 5y: No significant associations \\
\hline $\begin{array}{l}\text { Mihrshahi, } 2007 \text { (16); Prospective Cohort } \\
\text { Study; Australia; N: } 516\end{array}$ & $<3,>3 \mathrm{mo}$ & Atopic dermatitis at 5y: No significant associations \\
\hline
\end{tabular}

Atopic dermatitis (doctor-diagnosed and symptomatic) at 4y: No significant associations

Atopic dermatitis between $53-104 w k$ : $5.4 \%$ vs. $17 \%$ vs. $18 \% ; x 2=7.5$,

$P<0.05$

Atopic dermatitis between 0-13, 14-26, 27-39, 40-52wk: No significant associations

Atopic dermatitis at 18mo: No significant associations

(




\begin{tabular}{|c|c|c|}
\hline $\begin{array}{l}\text { Reference }{ }^{1} ; \text { Study design; Country; Sample } \\
\text { size }\end{array}$ & Age of CFB introduction & Results \\
\hline $\begin{array}{l}\text { O'Donovan, } 2016 \text { (17); Prospective Cohort } \\
\text { Study; United Kingdom; N: } 709\end{array}$ & $<17,>26 w k$ & Atopic dermatitis at $12 \mathrm{mo}$ : No significant associations \\
\hline $\begin{array}{l}\text { Poysa, } 1989 \text { (18); Prospective Cohort Study; } \\
\text { Finland; N: } 70\end{array}$ & $<3,3-6,>6 \mathrm{mo}$ & Atopic dermatitis at 5y: No significant associations \\
\hline $\begin{array}{l}\text { Sandini, } 2011 \text { (6); Prospective Cohort Study; } \\
\text { Finland; N: } 925 \text { at 2y, } 891 \text { at 5y. }\end{array}$ & Categories not defined & Atopic dermatitis at 2y and 5y: No significant associations \\
\hline $\begin{array}{l}\text { Schoetzau, } 2002 \text { (19); Prospective Cohort } \\
\text { Study; Germany; N: } 1121\end{array}$ & $1-16,17-24,>24 w k$ & Atopic dermatitis at 1y: No significant associations \\
\hline \multirow[t]{2}{*}{$\begin{array}{l}\text { Snijders, } 2008 \text { (20); Prospective Cohort } \\
\text { Study; The Netherlands; N: } 2558\end{array}$} & $<3,4-6,>7 \mathrm{mo}$ & $\begin{array}{l}\text { Atopic dermatitis at } 2 \mathrm{y}: 3 \text { vs 4-6mo: OR=1.28, 95\% Cl: } 0.91,1.81) ; 3 \text { vs } \\
\text { >7mo: } \mathrm{OR}=2.1,95 \% \mathrm{Cl}: 1.17,3.76 ; \mathrm{P}=0.02\end{array}$ \\
\hline & & $\begin{array}{l}\text { Atopic dermatitis at } 2 \mathrm{y}: 3 \text { vs } 4-6 \mathrm{mo}: \mathrm{OR}=2.67,95 \% \mathrm{Cl}: 0.80,8.97 ; 3 \text { vs > } \\
7 \mathrm{mo}: \mathrm{OR}=9.46,95 \% \mathrm{Cl}: 2.05,43.61 ; \mathrm{P}=0.00\end{array}$ \\
\hline $\begin{array}{l}\text { Taylor-Robinson, } 2016 \text { (21); Prospective } \\
\text { Cohort Study; United Kingdom; N: } 11537\end{array}$ & $<4,>4 \mathrm{mo}$ & Atopic dermatitis at 5y: OR=1.13, 95\% Cl: $1.04,1.23$ \\
\hline $\begin{array}{l}\text { Van Asperen, } 1984 \text { (22); Prospective Cohort } \\
\text { Study; Australia; N: } 79\end{array}$ & $<4,>4 \mathrm{mo}$ & Atopic dermatitis at 20mo: No significant associations \\
\hline $\begin{array}{l}\text { Zutavern, } 2006 \text { (23); Prospective Cohort } \\
\text { Study; Germany; N: } 2612\end{array}$ & $0-4,5-6,>6 \mathrm{mo}$ & Atopic dermatitis at 2y: No significant associations \\
\hline $\begin{array}{l}\text { Zutavern, } 2008 \text { (24); Prospective Cohort } \\
\text { Study; Germany; N: } 2073\end{array}$ & $<4,4-6,>6 \mathrm{mo}$ & Atopic dermatitis at 6y: No significant associations \\
\hline \multicolumn{3}{|l|}{ ASTHMA } \\
\hline $\begin{array}{l}\text { Fergusson, } 1983 \text { (26); Prospective Cohort } \\
\text { Study; New Zealand; N: } 1110\end{array}$ & $<4,>4 \mathrm{mo}$ & Asthma at 4y: No significant associations \\
\hline $\begin{array}{l}\text { Hetzner, } 2009 \text { (27); Prospective Cohort Study; } \\
\text { United States; N: } 7900\end{array}$ & $<6,>6 \mathrm{mo}$ & Asthma at 2y: No significant associations \\
\hline $\begin{array}{l}\text { Kajosaari, } 1994 \text { (3); Prospective Cohort } \\
\text { Study; Finland; N: } 135\end{array}$ & $\sim 3,6 \mathrm{mo}$ & Asthma at 5y: No significant associations \\
\hline $\begin{array}{l}\text { Mihrshahi, } 2007 \text { (16); Prospective Cohort } \\
\text { Study; Australia; N: 516 }\end{array}$ & $<3,>3 \mathrm{mo}$ & Asthma at 5y: No significant associations \\
\hline
\end{tabular}




\begin{tabular}{|c|c|c|}
\hline $\begin{array}{l}\text { Reference }{ }^{1} \text {; Study design; Country; Sample } \\
\text { size }\end{array}$ & Age of CFB introduction & Results \\
\hline $\begin{array}{l}\text { Nathan, } 2012 \text { (28); Case-Control Study; } \\
\text { Malaysia; Asthma Cases: 78, Controls: } 78\end{array}$ & $<6,>6 \mathrm{mo}$ & Asthma cases vs.controls: $65 \%$ vs. $33 \% ; \mathrm{P}<0.001$ \\
\hline $\begin{array}{l}\text { Sandini, } 2011 \text { (6); Prospective Cohort Study; } \\
\text { Finland; N: } 925 \text { at 2y, } 891 \text { at 5y }\end{array}$ & Categories not defined & Asthma at $2 y$ and 5y: No significant associations \\
\hline $\begin{array}{l}\text { Wilson, } 1998 \text { (29); Prospective Cohort Study; } \\
\text { Australia; N: } 545\end{array}$ & $:<15,>15 w k$ & Asthma at $\sim 7 y:$ No significant associations \\
\hline $\begin{array}{l}\text { Zutavern, } 2008 \text { (24); Prospective Cohort } \\
\text { Study; Germany; N: } 2073\end{array}$ & $<4,4-6,>6 \mathrm{mo}$ & Asthma at 6y: No significant associations \\
\hline \multicolumn{3}{|l|}{ ALLERGIC RHINITIS } \\
\hline $\begin{array}{l}\text { Kajosaari, } 1994 \text { (3); Prospective Cohort } \\
\text { Study; Finland; N: } 135\end{array}$ & $\sim 3,6 \mathrm{mo}$ & Allergic rhinitis at $5 y: 37 \%$ vs. $20 \% ; P=0.04$ \\
\hline $\begin{array}{l}\text { Sandini, } 2011 \text { (6); Prospective Cohort Study; } \\
\text { Finland; N: } 925 \text { at 2y, } 891 \text { at 5y }\end{array}$ & Categories not defined & Allergic rhinitis at 2y and 5y: No significant associations \\
\hline $\begin{array}{l}\text { Van Asperen, } 1984 \text { (22); Prospective Cohort } \\
\text { Study; Australia; N: } 79\end{array}$ & $<4,>4 \mathrm{mo}$ & Allergic rhinitis at 20mo: No significant associations \\
\hline $\begin{array}{l}\text { Zutavern, } 2008 \text { (24); Prospective Cohort } \\
\text { Study; Germany; N: } 2073\end{array}$ & $<4,4-6,>6 \mathrm{mo}$ & Allergic rhinitis at 6y: No significant associations \\
\hline \multicolumn{3}{|l|}{ ATOPIC DISEASE } \\
\hline $\begin{array}{l}\text { Kajosaari, } 1994 \text { (3); Prospective Cohort } \\
\text { Study; Finland; N: } 135\end{array}$ & $\sim 3,6 \mathrm{mo}$ & Atopic disease at 5y: No significant associations \\
\hline $\begin{array}{l}\text { Poysa, } 1991 \text { (30); Prospective Cohort Study; } \\
\text { Finland; N: } 68\end{array}$ & $<3,3-6,>6 \mathrm{mo}$ & Atopic disease at 9y: No significant associations \\
\hline $\begin{array}{l}\text { Yung, } 2015 \text { (31); Case-Control Study; China } \\
\text { (Hong Kong); Atopic Cases: 71, Controls: } 135\end{array}$ & Categories not defined & Atopic disease, cases vs. controls: No significant associations \\
\hline
\end{tabular}




\section{ANALYTIC FRAMEWORK}

The analytic framework (Figure 1) illustrates the overall scope of the systematic review, including the population, the interventions and/or exposures, comparators, and outcomes of interest. It also includes definitions of key terms and identifies key confounders considered in the systematic review. The analytic framework in Figure 1 is for systematic reviews conducted to examine the relationship between complementary feeding and food allergy, atopic dermatitis/eczema, asthma, and allergic rhinitis

\section{Figure 1: Analytic framework}

\begin{tabular}{|c|c|c|c|}
\hline \multicolumn{2}{|l|}{ Target Population } & \multicolumn{2}{|l|}{ Key Definitions } \\
\hline \multicolumn{2}{|c|}{$\begin{array}{l}\text { Generally healthy infants fed human milk, infant formula, or both, } \\
\text { examined through age } 18 \text { years }\end{array}$} & \multirow{4}{*}{\multicolumn{2}{|c|}{$\begin{array}{l}\text { Complementary feeding is defined as the process that starts when } \\
\text { human milk or infant formula is complemented by other foods and } \\
\text { beverages. The complementary feeding period typically continues to } 24 \\
\text { months as the young child transitions fully to family foods. } \\
\text { Complementary foods and beverages (CFB) are food and beverages } \\
\text { (liquids, semisolids, and solids) other than human milk or infant formula } \\
\text { provided to an infant or young child to provide nutrients and energy. }\end{array}$}} \\
\hline & $\downarrow$ & & \\
\hline Intervention/Exposure & Comparator & & \\
\hline $\begin{array}{l}\text { - Timing of introduction of } \\
\text { complementary foods } \\
\text { and beverages (CFB) }\end{array}$ & $\begin{array}{l}\text { Different timing of introduction } \\
\text { of CFB }\end{array}$ & & \\
\hline \multirow[t]{2}{*}{$\begin{array}{l}\text { - Types and amounts of } \\
\text { CFB }\end{array}$} & $\begin{array}{l}\text { Different types and amounts } \\
\text { of CFB }\end{array}$ & Key Confounders & Other Confounders \\
\hline & $\downarrow$ & - Education & - Maternal age \\
\hline \multicolumn{2}{|l|}{ Health Outcomes } & - Socioeconomic status & - Maternal diet \\
\hline \multirow{2}{*}{\multicolumn{2}{|c|}{$\begin{array}{l}\text { - Incidence, prevalence, and/or severity of: } \\
\text { o Food allergy } \\
\circ \text { Atopic dermatitis/eczema } \\
\text { ○ Asthma } \\
\circ \text { Allergic rhinitis }\end{array}$}} & $\begin{array}{l}\text { - Race and/or ethnicity } \\
\text { Milk feeding practices } \\
\text { (breast milk, infant } \\
\text { formula, or both) } \\
\text { - Birth size }\end{array}$ & $\begin{array}{l}\text { - Maternal parity } \\
\text { - Childcare arrangement } \\
\text { - Marital status/head of household } \\
\text { - Medical support/access } \\
\text { - Participation in a supplemental }\end{array}$ \\
\hline & & $\begin{array}{l}\text { - Cigarette smoke exposure } \\
\text { - Atopic risk status } \\
\text { - Household pets }\end{array}$ & $\begin{array}{l}\text { food program } \\
\text { - Home environment } \\
\text { - Rural or urban setting } \\
\text { - Antibiotic use }\end{array}$ \\
\hline
\end{tabular}

\section{SEARCH PLAN AND RESULTS}

\section{Inclusion and exclusion criteria}

The inclusion and exclusion criteria are a set of characteristics to determine which studies will be included or excluded in the systematic review. This table provides the inclusion and exclusion criteria for the systematic review question(s): What is the relationship between timing of introduction of complementary foods/beverages or types and amounts of complementary foods/beverages and food allergy, atopic dermatitis/eczema, asthma, and allergic rhinitis?

\section{Table 3. Inclusion and exclusion criteria}

\begin{tabular}{lll}
\hline \hline Category & Inclusion Criteria & Exclusion Criteria \\
\hline Study design & Randomized controlled trials & Cross-sectional studies \\
\hline
\end{tabular}




\begin{tabular}{|c|c|c|}
\hline Category & Inclusion Criteria & Exclusion Criteria \\
\hline & Non-randomized controlled trials & Uncontrolled studies \\
\hline & Prospective cohort studies & Pre/post studies without a control \\
\hline & Retrospective cohort studies & Narrative reviews \\
\hline & Case-control studies & Systematic reviews \\
\hline & Pre/post studies with a control & Meta-analyses \\
\hline \multirow[t]{2}{*}{$\begin{array}{l}\text { Independent } \\
\text { variable } \\
\text { (intervention or } \\
\text { exposure) }\end{array}$} & $\begin{array}{l}\text { Timing of introduction to complementary } \\
\text { foods and beverages (CFB) (i.e., foods } \\
\text { and beverages (liquids, semisolids, and } \\
\text { solids) other than human milk or infant } \\
\text { formula provided to an infant or young } \\
\text { child to provide nutrients and energy) }\end{array}$ & $\begin{array}{l}\text { Consumption of fluid cow's milk before } 12 \text { months of } \\
\text { age }\end{array}$ \\
\hline & Types or amounts of CFB & \\
\hline \multirow[t]{2}{*}{ Comparator } & Different timing of introduction of CFB & \\
\hline & Different types and amounts of CFB & \\
\hline \multirow[t]{2}{*}{$\begin{array}{l}\text { Dependent } \\
\text { variables } \\
\text { (outcomes) }\end{array}$} & $\begin{array}{l}\text { Incidence, prevalence, and/or severity } \\
\text { of: food allergy, atopic } \\
\text { dermatitis/eczema, asthma, and/or } \\
\text { allergic rhinitis }\end{array}$ & $\begin{array}{l}\text { Food allergy when diagnosis was based solely on } \\
\text { food allergen sensitization (i.e., skin prick test, or } \\
\text { serum IgE measure) }\end{array}$ \\
\hline & & $\begin{array}{l}\text { Asthma when diagnosis was based solely on report } \\
\text { of wheeze }\end{array}$ \\
\hline Date range & January 1980 - February 2017 & \\
\hline Language & Studies published in English & Studies published in languages other than English \\
\hline $\begin{array}{l}\text { Publication } \\
\text { status }\end{array}$ & $\begin{array}{l}\text { Studies published in peer-reviewed } \\
\text { journals }\end{array}$ & $\begin{array}{l}\text { Grey literature, including unpublished data, } \\
\text { manuscripts, reports, abstracts, conference } \\
\text { proceedings }\end{array}$ \\
\hline Country ${ }^{1,2,3}$ & $\begin{array}{l}\text { Studies conducted in Very High or High } \\
\text { Human Development Countries }\end{array}$ & $\begin{array}{l}\text { Studies conducted in Medium or Low Human } \\
\text { Development Countries }\end{array}$ \\
\hline \multirow[t]{3}{*}{$\begin{array}{l}\text { Study } \\
\text { participants }\end{array}$} & Human subjects & $\begin{array}{l}\text { Hospitalized patients, not including birth and } \\
\text { immediate post-partum hospitalization of healthy } \\
\text { babies }\end{array}$ \\
\hline & Males & \\
\hline & Females & \\
\hline \multirow[t]{2}{*}{$\begin{array}{l}\text { Age of study } \\
\text { participants }\end{array}$} & $\begin{array}{l}\text { Age at intervention or exposure: Infants } \\
(0-12 \mathrm{mo}) \text {; Toddlers (12-24mo) }\end{array}$ & $\begin{array}{l}\text { Age at intervention or exposure: Child (2-5 years } \\
\text { (y)); Child (6-12y); Adolescents (13-18y); Adults } \\
\text { (19y and older); Older adults ( } 65 \text { to } 79 y) ; \text { Older } \\
\text { adults }(80+y)\end{array}$ \\
\hline & $\begin{array}{l}\text { Age at outcome: Infants }(0-12 \mathrm{mo} \text {; food } \\
\text { allergy, atopic dermatitis, allergic } \\
\text { rhinitis); Toddlers (12-24mo; food } \\
\text { allergy, atopic dermatitis, allergic } \\
\text { rhinitis); Child ( } 2-5 \text { years (y)); Child (6- } \\
\text { 12y); Adolescents (13-18y) }\end{array}$ & $\begin{array}{l}\text { Age at outcome: Infants ( } 0-12 \text { months) (asthma); } \\
\text { Toddlers ( } 12-24 \text { months) (asthma); Adults ( } 19 y \text { and } \\
\text { older); Older adults ( } 65 \text { to } 79 y) \text {; Older adults ( } 80+y)\end{array}$ \\
\hline $\begin{array}{l}\text { Health status of } \\
\text { study } \\
\text { participants }\end{array}$ & $\begin{array}{l}\text { Studies done in generally healthy } \\
\text { populations }\end{array}$ & $\begin{array}{l}\text { Studies that exclusively enroll subjects with a } \\
\text { disease or with the health outcome of interest }\end{array}$ \\
\hline
\end{tabular}




\begin{tabular}{lll}
\hline \hline Category & Inclusion Criteria & Exclusion Criteria \\
\hline $\begin{array}{l}\text { Studies done in populations where } \\
\text { infants were full term ( } \geq 37 \text { wk gestational } \\
\text { age) }\end{array}$ & $\begin{array}{l}\text { Studies done in hospitalized or malnourished } \\
\text { subjects }\end{array}$ \\
$\begin{array}{l}\text { Studies done in populations with } \\
\text { elevated chronic disease risk, or that } \\
\text { enroll some participants with a disease } \\
\text { or with the health outcome of interest }\end{array}$ & $\begin{array}{l}\text { Studies of exclusively pre-term babies (gestational } \\
\text { age }<37 \text { wh) or babies that are small for gestational } \\
\text { age (<2500g) }\end{array}$ \\
& $\begin{array}{l}\text { Studies of subjects with infectious diseases (e.g. } \\
\text { HIV/AIDS) (or with mothers diagnosed with an }\end{array}$ \\
infectious disease)
\end{tabular}

\section{Search terms and electronic databases used}

PubMed, US National Library of Medicine (1966 to 8 February 2017):

Date(s) Searched: 2/8/2017

Search Terms:

Date range searched: $1980-2 / 8 / 17$

(Complementary OR supplementary OR wean* OR transition* OR introduc* OR "Infant Nutritional Physiological Phenomena"[Mesh:noexp] OR weaning[mesh] OR bottle*)

AND (feeding* OR food* OR beverage*[tiab] OR beverages[mh] OR eating OR $\operatorname{diet}[$ tiab] OR diet[mh] OR meal*[tiab] OR meals[mh] OR "Food and Beverages"[Mesh] OR diets[tiab] OR cereal*[tiab] OR "Edible Grain"[Mesh] OR bread*[tiab] OR whole grain* OR juice*[tiab] OR milk[tiab] OR "Milk"[Mesh] OR dairy[tiab] OR "Dairy Products"[Mesh] OR meat[tiab] OR cheese[tiab] OR yogurt[tiab] OR yoghurt*[tiab] OR fruit*[tiab] OR "Fruit"[Mesh] OR vegetable*[tiab] OR "Vegetables"[Mesh] OR egg*[tiab] OR "Eggs"[Mesh] OR nut[tiab] OR nuts[tiab] OR peas[tiab] OR beans[tiab] OR legume*[tiab] OR snack*[tiab] OR bread[mh] OR honey[mh] OR vegetable*[tiab] OR "Vegetables"[Mesh] OR egg*[tiab] OR "Eggs"[Mesh:noexp] OR "egg white"[mh] OR "egg yolk"[mh] OR snack*[tiab] OR candy[mh] OR "Fast Foods"[Mesh] OR meat[mh] OR molasses[mh] OR nuts[mh] OR "Raw Foods"[Mesh] OR seeds[mh])

OR

"infant food"[mesh] OR infant feed* OR Bottle feeding[mh] OR bottle feeding*[tiab] OR bottle feeding OR bottle-feeding*[tiab] OR bottle-feedings OR bottle-fed[tiab] OR "bottle fed"[tiab] OR solid food* 
NOT (editorial[ptyp] OR comment[ptyp] OR news[ptyp] OR letter[ptyp] OR review[ptyp] OR systematic[sb])

("Study Characteristics" [Publication Type] OR "clinical trial"[ptyp] OR "Epidemiologic Studies"[Mesh] OR "Support of Research"[ptyp] OR cohort[tiab] OR observational[tiab] OR retrospective[tiab] OR longitudinal[tiab] OR trial[tiab] OR trials[tiab] OR case control*[tiab] OR case-control*[tiab] OR before-after stud*[tiab] OR before after stud*[tiab]

(includes age filter: Filters: Infant: birth-23 months and preschool child 2-5 yrs)

OR ((Solid food*) OR solids))

AND

(("Allergy and Immunology"[Mesh:NoExp] OR allergy[tiab] OR allergies[tiab] OR allergic[tiab] OR Hypersensitivit*[tiab]) AND (food OR peanut* OR nut OR nuts OR egg OR eggs OR milk OR shellfish OR wheat)) OR "Food Hypersensitivity"[Mesh] OR asthma OR "Rhinitis, Allergic"[Mesh] OR (allergic[tiab] AND Rhiniti*[tiab]) OR "Dermatitis, Atopic"[Mesh] OR ((Dermatiti*[tiab] OR eczema[tiab]) AND Atopic[tiab]) OR (Infant* AND Eczema) OR "Immunoglobulin E"[Mesh] OR "Immunoglobulin E"[tiab] OR IgE[tiab]

for nonmedline[sb]: NOT animals by: NOT (sheep[ti] OR lamb[ti] OR lambs[ti] OR calving[ti] OR calves[ti] OR mice[ti] OR mouse[ti] OR pigs[ti] OR cows[ti] OR piglets[ti] OR cow[ti] OR piglet[ti] OR monkey[ti] OR rats[ti] OR rat[ti] OR animal*[ti])

infant* OR baby OR babies OR toddler* OR newborn*[tiab] OR "Child, Preschool"[Mesh] OR preschool*[tiab] OR pre-school*[tiab] OR "early childhood"[tiab] OR early year*[tiab] OR pre-k[tiab] OR pre-primary[tiab] OR under five*[ti] OR young child*[ti] OR prekindergarten[tiab] OR pre-kindergarten[tiab] OR weanling* OR "first two years" OR "first 2 years"

\section{Embase, Elsevier (1947 to February 2017):}

Date(s) Searched: 2/2017

Search Terms:

'complementary feeding'/exp OR

(Complementary OR supplementa* OR wean* OR transition* OR introduc* OR family) NEAR/3 (feed ${ }^{\star}$ OR food ${ }^{\star}$ OR beverage* OR eating OR diet)

OR

(Complementary OR transition* OR introduct* OR wean*) AND (food/exp OR 'baby food'/exp OR 'cereal'/exp OR 'dairy product'/exp OR 'egg'/exp OR 'fruit'/exp OR 
'meat'/exp OR 'sea food'/exp OR 'milk'/exp OR fish/exp OR 'poultry'/exp OR 'beverage'/exp OR 'vegetable'/exp OR nut/exp OR pea/exp OR meal/exp OR 'infant feeding'/exp)

OR

(Complementary OR supplementa* OR wean* OR transition* OR introduc*) NEAR/5 ('whole grain' OR 'whole grains' OR dairy OR egg OR eggs OR meat OR poultry OR seafood OR fruit* OR milk OR fish* OR poultry OR beverage* OR vegetables* OR pea OR peas OR nut OR nuts OR cereal OR bread* OR yog*urt* OR cheese* OR juice* OR rice OR soup OR legume* OR snack* OR meal*)

OR 'baby food'/de OR (solid NEAR/2 food*):ab,ti

AND

(infant*:ti,ab OR infant/exp) OR (baby OR babies OR toddler* OR newborn* OR nurser*):ti,ab OR 'newborn'/exp OR 'newborn care'/exp OR preschool*:ti,ab OR preschool:ti,ab OR 'preschool child'/exp OR 'infancy'/exp OR "early childhood":ti,ab OR "early years" OR pre-k:ti,ab OR 'nursery'/exp OR 'nursery school'/exp OR prekindergarten:ti,ab OR pre-kindergarten:ti,ab OR weanling* (includes limits below) OR ([newborn]/lim OR [infant]/lim OR [child]/lim OR [preschool]/lim)

AND ([in process]/lim OR [article]/lim OR [article in press]/lim) AND ([embase]/lim NOT [medline]/lim)

Limit to humans:

AND

'allergic asthma'/exp OR 'food allergy'/exp OR 'allergic rhinitis'/exp OR 'dermatitis'/exp OR 'eczema'/exp OR 'skin allergy'/exp OR ((allerg* OR hypersensitivity*) NEAR/3 (food OR peanut* OR nut OR nuts OR egg OR milk OR shellfish OR wheat)) OR 'immunoglobulin E'/exp OR 'immunoglobulin E':ti,ab OR 'atopy'/exp OR atopy:ti,ab OR atopic:ti,ab OR IgE:ti,ab

\section{Cochrane Central Register of Controlled Trials, John Wiley \& Sons in the Cochrane Library (searched 9 February 2017):}

Date(s) Searched: 2/9/17

Search Terms:

(feed* OR food* OR beverage* OR diet* OR 'whole grain' OR 'whole grains' OR dairy OR egg OR meat OR poultry OR seafood OR fruit* OR milk OR fish* OR poultry OR vegetables* OR pea OR beans OR legume* OR nut OR cereal OR beverage* OR

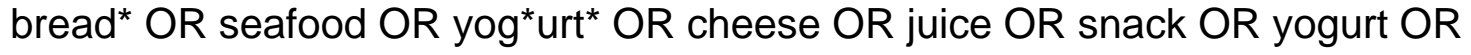
yoghurt OR nut OR nuts OR honey OR meal OR meals) NEAR/3 (Complementary OR supplementa* OR wean* OR transition* OR introduct* OR family)

OR 
[mh ^"Infant Nutritional Physiological Phenomena"] OR [mh weaning] OR ((bottle*) NOT (milk OR formula))

AND ([mh beverages] OR [mh eating] OR [mh diet] OR [mh meals] OR [mh "Food and Beverages"] OR [mh "Edible Grain"] OR [mh "Milk"] OR dairy:ti,ab OR [mh "Dairy Products"] OR [mh "Fruit"] OR [mh "Vegetables"] OR [mh "Eggs"] OR [mh bread] OR [mh honey] OR [mh "Vegetables"] OR [mh ^"Eggs"] OR [mh "egg white"] OR [mh "egg yolk"] OR [mh candy] OR [mh "Fast Foods"] OR [mh meat] OR [mh molasses] OR [mh nuts] OR [mh "Raw Foods"] OR [mh seeds])

OR

((Infant* OR baby* OR babies) NEAR/2 food*):ti,ab OR [mh "infant food"]

AND

[mh ^"Allergy and Immunology"] OR ((allerg*:ti,ab OR Hypersensitivit*:ti,ab) AND (food OR peanut OR nut OR nuts OR egg OR milk OR shellfish OR wheat)) OR [mh "Food Hypersensitivity"] OR asthma* OR [mh" Rhinitis, Allergic"] OR (allerg* NEAR/5 Rhiniti*) OR [mh "Dermatitis, Atopic"] OR ((Dermatiti* OR eczema) NEAR/5 Atopic) OR (Infant* NEAR/5 Eczema) OR [mh "Immunoglobulin E"] OR "Immunoglobulin E":ti,ab OR $\lg \mathrm{E}: \mathrm{ti}, \mathrm{ab}$

CINAHL Plus with Full Text, EBSCO (Cumulative Index to Nursing and Allied Health Literature; 1937 to 9 February 2017):

Date(s) Searched: 2/9/17

Search Terms:

209; selected 26 for downloading

(MH "Food Hypersensitivity+") OR (MH "Milk Hypersensitivity") OR (MH "Pollen-Food Allergy") OR (MH "Rhinitis, Atrophic") OR "Immunoglobulin e" OR (MH "Eczema") OR (MH "Dermatitis, Atopic")

AND

(MH "Food and Beverages+") OR (MH "Food") OR (MH "Diet") OR (MH "Eating") OR (MH "Eating Behavior") OR (MH "Taste") OR (MH "Taste Buds") OR (MH "Cereals") OR (MH "Dairy Products") OR (MH "Yogurt") OR (MH "Cheese") OR (MH "Milk") OR (MH "Eggs") OR (MH "Fruit") OR (MH "Fruit Juices") OR (MH "Meat") OR (MH "Seafood") OR (MH "Fish") OR (MH "Poultry") OR (MH "Vegetables") OR (MH "Nuts") OR (MH "Legumes") OR (MH "Bread") AND (Complementary OR supplementa* OR wean* OR transition* OR introduc*)

OR

('whole grain' OR 'whole grains' OR dairy OR egg OR eggs OR meat OR poultry OR seafood OR fruit* OR milk OR fish* OR poultry OR vegetables* OR pea OR peas OR nut OR nuts OR cereal OR beverage* OR bread* OR seafood OR yog*urt* OR cheese* OR juice*) N5 (Complementary OR supplementa* OR wean* OR transition* 
OR introduc* OR family)

OR (Infant* OR baby OR babies) N3 food*

\section{Figure 2: Flow chart of literature search and screening results}

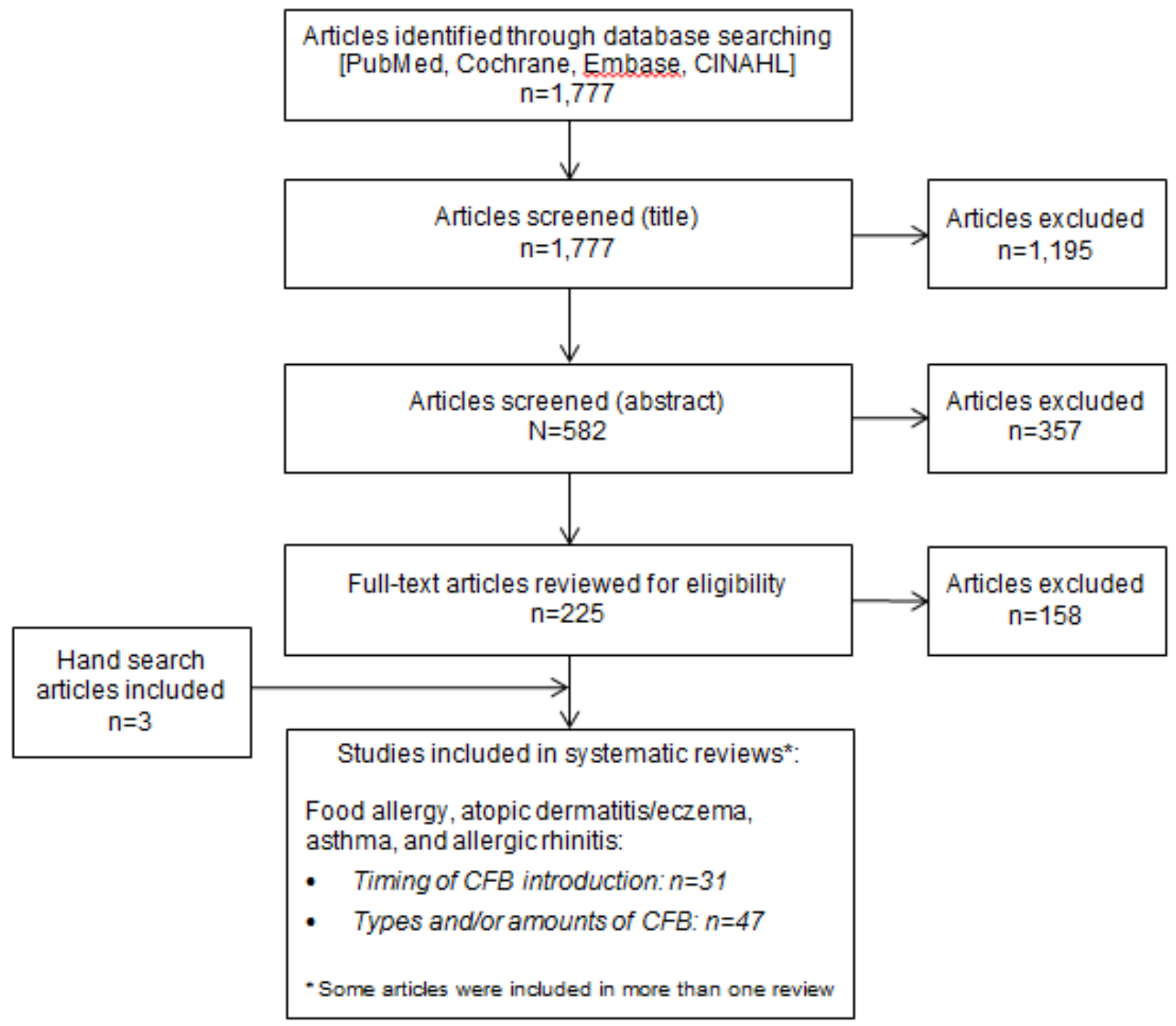

This flow chart illustrates the literature search and screening results for articles examining the relationship between complementary feeding and food allergy, atopic dermatitis/eczema, asthma, and allergic rhinitis. The results of the electronic database searches were screened independently by two NESR analysts in a step-wise manner by reviewing titles, abstracts, and full text articles to determine which articles met the criteria for inclusion. A manual search was done to ascertain articles not identified through the electronic database search. The systematic review on timing of CFB introduction included 31 articles, and the systematic review on on types and amounts of CFB consumed included 47 articles. 


\section{Excluded articles}

The table below lists the excluded articles with at least one reason for exclusion, and may not reflect all possible reasons.

\section{Table 4. Excluded articles}

\begin{tabular}{|c|c|c|}
\hline & Citation & Reasons for Exclusion \\
\hline 1 & Children's peanut allergies arising at younger ages. AORN Journal. 2008;87:624-624. & Study design \\
\hline 2 & Infants with food protein allergy tolerate soy milk earlier than cow's. Community Practitioner. 2009;82:41-41. & Study design \\
\hline 3 & Significance of food hypersensitivity in children with atopic dermatitis. Pediatr Dermatol. 1986;3:161-74. & Study design \\
\hline 4 & $\begin{array}{l}\text { Aberg, N.,Engstrom, I.,Lindberg, U.. Allergic diseases in Swedish school children. Acta Paediatr Scand. } \\
\text { 1989;78:246-52. }\end{array}$ & Study design \\
\hline 5 & $\begin{array}{l}\text { Abrams, E. M.,Becker, A. B.. Introducing solid food: age of introduction and its effect on risk of food allergy and } \\
\text { other atopic diseases. Can Fam Physician. 2013;59:721-2. }\end{array}$ & Study design \\
\hline 6 & $\begin{array}{l}\text { Alper, Z.,Sapan, N.,Ercan, I.,Canitez, Y.,Bilgel, N.. Risk factors for wheezing in primary school children in Bursa, } \\
\text { Turkey. Am J Rhinol. 2006;20:53-63. }\end{array}$ & Study design \\
\hline 7 & $\begin{array}{l}\text { Armentia, A.,Rodriguez, R.,Callejo, A.,Martin-Esteban, M.,Martin-Santos, J. M.,Salcedo, G.,Pascual, C.,Sanchez- } \\
\text { Monge, R.,Pardo, M.. Allergy after ingestion or inhalation of cereals involves similar allergens in different ages. Clin } \\
\text { Exp Allergy. 2002;32:1216-22. }\end{array}$ & $\begin{array}{l}\text { Health Status, } \\
\text { Independent Variable }\end{array}$ \\
\hline 8 & $\begin{array}{l}\text { Arshad, S. H.,Matthews, S.,Gant, C.,Hide, D. W.. Effect of allergen avoidance on development of allergic disorders } \\
\text { in infancy. Lancet. 1992;339:1493-7. }\end{array}$ & Independent Variable \\
\hline 9 & $\begin{array}{l}\text { Bardara, M.,Varin, E.,Zani, G.. Response to diet in } 130 \text { children affected with atopic dermatitis. Allergy. 1989:147- } \\
50 .\end{array}$ & Study design \\
\hline 10 & $\begin{array}{l}\text { Bardare, M.,Vaccari, A.,Allievi, E.,Brunelli, L.,Coco, F.,de Gaspari, G. C.,Flauto, U.. Influence of dietary } \\
\text { manipulation on incidence of atopic disease in infants at risk. Ann Allergy. 1993;71:366-71. }\end{array}$ & Independent Variable \\
\hline 11 & $\begin{array}{l}\text { Becker, A.,Watson, W.,Ferguson, A.,Dimich-Ward, H.,Chan-Yeung, M.. The Canadian asthma primary prevention } \\
\text { study: outcomes at } 2 \text { years of age. J Allergy Clin Immunol. 2004;113:650-6. }\end{array}$ & $\begin{array}{l}\text { Study design, Independent } \\
\text { Variable }\end{array}$ \\
\hline 12 & $\begin{array}{l}\text { Benn, C. S.,Wohlfahrt, J.,Aaby, P.,Westergaard, T.,Benfeldt, E.,Michaelsen, K. F.,Bjorksten, B.,Melbye, M.. } \\
\text { Breastfeeding and risk of atopic dermatitis, by parental history of allergy, during the first } 18 \text { months of life. Am J } \\
\text { Epidemiol. 2004;160:217-23. }\end{array}$ & Independent Variable \\
\hline 13 & $\begin{array}{l}\text { Berg, Av,Kramer, U.,Link, E.,Bollrath, C.,Heinrich, J.,Brockow, I.,Koletzko, S.,Grubl, A.,Filipiak-Pittroff, } \\
\text { B.,Wichmann, H. E.,Bauer, C. P.,Reinhardt, D.,Berdel, D.. Impact of early feeding on childhood eczema: }\end{array}$ & Independent Variable \\
\hline
\end{tabular}




\begin{tabular}{|c|c|c|}
\hline & Citation & Reasons for Exclusion \\
\hline & $\begin{array}{l}\text { development after nutritional intervention compared with the natural course - the GINIplus study up to the age of } 6 \\
\text { years. Clin Exp Allergy. 2010;40:627-36. }\end{array}$ & \\
\hline 14 & $\begin{array}{l}\text { Bergmann, R. L.,Bergmann, K. E.,Lau-Schadensdorf, S.,Luck, W.,Dannemann, A.,Bauer, C. P.,Dorsch, W.,Forster, } \\
\text { J.,Schmidt, E.,Schulz, J.,et, al. Atopic diseases in infancy. The German multicenter atopy study (MAS-90). Pediatr } \\
\text { Allergy Immunol. 1994;5:19-25. }\end{array}$ & Independent Variable \\
\hline 15 & $\begin{array}{l}\text { Bilenko, N.,Ghosh, R.,Levy, A.,Deckelbaum, R. J.,Fraser, D.. Partial breastfeeding protects Bedouin infants from } \\
\text { infection and morbidity: prospective cohort study. Asia Pac J Clin Nutr. 2008;17:243-9. }\end{array}$ & Independent Variable \\
\hline 16 & $\begin{array}{l}\text { Bion, V.,Lockett, G. A.,Soto-Ramírez, N.,Zhang, H.,Venter, C.,Karmaus, W.,Holloway, J. W.,Arshad, S. H.. } \\
\text { Evaluating the efficacy of breastfeeding guidelines on long-term outcomes for allergic disease. Allergy: European } \\
\text { Journal of Allergy and Clinical Immunology. 2016;71:661-670. }\end{array}$ & Independent Variable \\
\hline 17 & Birkbeck, J. A.. Goat milk in infant nutrition. N Z Med J. 1984;97:413-4. & Study design \\
\hline 18 & Blumberg, S.. Infant feeding: can we spice it up a bit?. J Am Diet Assoc. 2006;106:504-5. & Study design \\
\hline 19 & $\begin{array}{l}\text { Bruno, G.,Milita, O.,Ferrara, M.,Nisini, R.,Cantani, A.,Businco, L.. Prevention of atopic diseases in high risk babies } \\
\text { (long-term follow-up). Allergy Proc. 1993;14. }\end{array}$ & Independent Variable \\
\hline 20 & $\begin{array}{l}\text { Burks, K.,Jones, S.. The Canadian asthma primary prevention study: Outcomes at } 2 \text { years of age. Pediatrics. } \\
\text { 2005;116:537-4005. }\end{array}$ & Study design \\
\hline 21 & $\begin{array}{l}\text { Burr, M. L.,Limb, E. S.,Maguire, M. J.,Amarah, L.,Eldridge, B. A.,Layzell, J. C.,Merrett, T. G.. Infant feeding, } \\
\text { wheezing, and allergy: a prospective study. Arch Dis Child. 1993;68:724-8. }\end{array}$ & Independent Variable \\
\hline 22 & $\begin{array}{l}\text { Burr, M. L.,Merrett, T. G.,Dunstan, F. D.,Maguire, M. J.. The development of allergy in high-risk children. Clin Exp } \\
\text { Allergy. 1997;27:1247-53. }\end{array}$ & Independent Variable \\
\hline 23 & Calamaro, C. J.. Infant nutrition in the first year of life: tradition or science?. Pediatr Nurs. 2000;26:211-5. & Study design \\
\hline 24 & Cant, A. J.,Bailes, J. A.. How should we feed the potentially allergic infant?. Hum Nutr Appl Nutr. 1984;38:474-6. & Study design \\
\hline 25 & Challacombe, D. N.. Allergies and infant feeding. Midwife Health Visit Community Nurse. 1986;22:164-6. & Study design \\
\hline 26 & $\begin{array}{l}\text { Chandra, R. K.. Role of maternal diet and mode of infant feeding in prevention of atopic dermatitis in high risk } \\
\text { infants. Allergy. 1989:135-9. }\end{array}$ & Study design \\
\hline 27 & $\begin{array}{l}\text { Chiu, C. Y.,Liao, S. L.,Su, K. W.,Tsai, M. H.,Hua, M. C.,Lai, S. H.,Chen, L. C.,Yao, T. C.,Yeh, K. W.,Huang, J. L.. } \\
\text { Exclusive or Partial Breastfeeding for } 6 \text { Months Is Associated with Reduced Milk Sensitization and Risk of Eczema } \\
\text { in Early Childhood. Medicine (United States). 2016;95. }\end{array}$ & Independent Variable \\
\hline 28 & $\begin{array}{l}\text { Cho, H. N.,Hong, S.,Lee, S. H.,Yum, H. Y.. Nutritional status according to sensitized food allergens in children with } \\
\text { atopic dermatitis. Allergy Asthma Immunol Res. 2011;3:53-7. }\end{array}$ & Study design \\
\hline
\end{tabular}




\begin{tabular}{|c|c|c|}
\hline & Citation & Reasons for Exclusion \\
\hline 29 & $\begin{array}{l}\text { Cudowska, B.,Marcinkiewicz, S.,Kaczmarski, M.. Sensitization to cereal allergens in children with atopic dermatitis. } \\
\text { Postepy Dermatologii i Alergologii. 2011;28:181-186. }\end{array}$ & $\begin{array}{l}\text { Study design, Health } \\
\text { Status }\end{array}$ \\
\hline 30 & de Looy, A. E.. Infant nutrition. Nursing (Lond). 1986;3:446-9. & Study design \\
\hline 31 & $\begin{array}{l}\text { del-Rio Camacho, G.,Martinez Jimenez, V.,Fernandez-Cantalejo Padial, J.. Absence of clinical symptoms upon } \\
\text { introduction of egg into the diet of milk-allergic infants not previously sensitised to egg. Allergol Immunopathol } \\
\text { (Madr). 2012;40:374-8. }\end{array}$ & $\begin{array}{l}\text { Health Status, } \\
\text { Independent Variable }\end{array}$ \\
\hline 32 & $\begin{array}{l}\text { Dieguez, M. C.,Cerecedo, I.,Muriel, A.,Zamora, J.,Sanchez-Cano, M.,De la Hoz, B.. Skin prick test predictive value } \\
\text { on the outcome of a first known egg exposure in milk-allergic children. Pediatr Allergy Immunol. 2008;19:319-24. }\end{array}$ & $\begin{array}{l}\text { Health Status, } \\
\text { Independent Variable }\end{array}$ \\
\hline 33 & $\begin{array}{l}\text { Du Toit, G.,Katz, Y.,Sasieni, P.,Mesher, D.,Maleki, S. J.,Fisher, H. R.,Fox, A. T.,Turcanu, V.,Amir, T.,Zadik-Mnuhin, } \\
\text { G.,Cohen, A.,Livne, I.,Lack, G.. Early consumption of peanuts in infancy is associated with a low prevalence of } \\
\text { peanut allergy. J Allergy Clin Immunol. 2008;122:984-91. }\end{array}$ & $\begin{array}{l}\text { Study design, Dependent } \\
\text { Variable }\end{array}$ \\
\hline 34 & $\begin{array}{l}\text { Dubakiene, R.,Rudzeviciene, O.,Butiene, I.,Sezaite, I.,Petronyte, M.,Vaicekauskaite, D.,Zvirbliene, A.. Studies on } \\
\text { early allergic sensitization in the Lithuanian birth cohort. ScientificWorldJournal. 2012;2012:909524. }\end{array}$ & Independent Variable \\
\hline 35 & $\begin{array}{l}\text { Duczmal, E.,Breborowicz, A.,Duczmal, T.. The influence of specific factors on the prevalence of allergic diseases in } \\
\text { a birth cohort study [polish]. Alergia Astma Immunologia. 2011;16:96-104. }\end{array}$ & Language \\
\hline 36 & $\begin{array}{l}\text { Dunlop, A. L., Reichrtova, E.,Palcovicova, L.,Ciznar, P.,Adamcakova-Dodd, A.,Smith, S. J.,McNabb, S. J.. } \\
\text { Environmental and dietary risk factors for infantile atopic eczema among a Slovak birth cohort. Pediatr Allergy } \\
\text { Immunol. 2006;17:103-11. }\end{array}$ & Study design \\
\hline 37 & Early peanut consumption may prevent allergy. Nurse Prescribing. 2008;6:509-509. & Study design \\
\hline 38 & $\begin{array}{l}\text { Exl, B. M.,Deland, U.,Secretin, M. C.,Preysch, U.,Wall, M.,Shmerling, D. H.. Improved general health status in an } \\
\text { unselected infant population following an allergen-reduced dietary intervention programme: the ZUFF-STUDY- } \\
\text { PROGRAMME. Part II: infant growth and health status to age } 6 \text { months. ZUg-FrauenFeld. Eur J Nutr. 2000;39:145- } \\
\text { 56. }\end{array}$ & Independent Variable \\
\hline 39 & $\begin{array}{l}\text { Fadeeva, T.,Asin, J. L.,Horrillo, M. L.,Baraut, T. G.,Vela, R. F., Conde, S. L.,Hontoria, O. E.,Valero, C. B.,Molina, A. } \\
\text { M.. Results of the oral egg-challenge test performed on two different groups of children. One group with a history, } \\
\text { suggestive of allergic reaction with egg intake and the other group sensitised to hen's egg without previous egg } \\
\text { intake. Allergol Immunopathol (Madr). 2010;38:233-40. }\end{array}$ & Independent Variable \\
\hline 40 & $\begin{array}{l}\text { Filipiak, B.,Zutavern, A.,Koletzko, S.,Von Berg, A.,Brockow, I.,Grübl, A.,Berdel, D., Reinhardt, D.,Bauer, C. } \\
\text { P.,Wichmann, H. E.,Heinrich, J.. Early solid food introduction and development of eczema in the first } 4 \text { years. } \\
\text { Results from the GINI birth cohort. Allergo Journal. 2008;17:82-83. }\end{array}$ & Language \\
\hline 41 & $\begin{array}{l}\text { Fiocchi, A.,Verga, M. C.. Early allergenic-food introduction does not reduce subsequent food allergy development. } \\
\text { J Pediatr. 2016;178:305-306. }\end{array}$ & Study design \\
\hline
\end{tabular}




\begin{tabular}{|c|c|c|}
\hline & Citation & Reasons for Exclusion \\
\hline 42 & $\begin{array}{l}\text { Flohr, C.,Nagel, G.,Weinmayr, G.,Kleiner, A.,Strachan, D. P.,Williams, H. C.. Lack of evidence for a protective effect } \\
\text { of prolonged breastfeeding on childhood eczema: lessons from the International Study of Asthma and Allergies in } \\
\text { Childhood (ISAAC) Phase Two. Br J Dermatol. 2011;165:1280-9. }\end{array}$ & Study design \\
\hline 43 & $\begin{array}{l}\text { Frank, L.,Marian, A.,Visser, M.,Weinberg, E.,Potter, P. C.. Exposure to peanuts in utero and in infancy and the } \\
\text { development of sensitization to peanut allergens in young children. Pediatr Allergy Immunol. 1999;10:27-32. }\end{array}$ & Country \\
\hline 44 & $\begin{array}{l}\text { Gabet, S.,Just, J.,Couderc, R.,Seta, N.,Momas, I.. Allergic sensitisation in early childhood: Patterns and related } \\
\text { factors in PARIS birth cohort. Int J Hyg Environ Health. 2016;219:792-800. }\end{array}$ & Dependent Variable \\
\hline 45 & $\begin{array}{l}\text { Geller-Bernstein, G.,Kenett, R.,Weisglass, L.,Tsur, S.,Lahav, M.,Levin, S.. Atopic babies with wheezy bronchitis. } \\
\text { Follow-up study relating prognosis to sequential IgE values, type of early infant feeding, exposure to parental } \\
\text { smoking and incidence of lower respiratory tract infections. Allergy. 1987;42:85-91. }\end{array}$ & $\begin{array}{l}\text { Health Status, } \\
\text { Independent Variable }\end{array}$ \\
\hline 46 & $\begin{array}{l}\text { Ghaderi, R.,Makhmalbaf, Z.. Effect of breast-feeding on the development of atopic dermatitis. Iranian Journal of } \\
\text { Allergy, Asthma and Immunology. 2005;4:129-132. }\end{array}$ & Independent Variable \\
\hline 47 & $\begin{array}{l}\text { Ghadi, A.,Dutau, G.,Rancé, F.. A sensitization study of atopic children in Marrakech. A prospective study of 160 } \\
\text { children between } 2002 \text { and } 2005 \text { [french]. Revue Francaise d'Allergologie et d'Immunologie Clinique. 2007;47:409- } \\
415 .\end{array}$ & Language \\
\hline 48 & $\begin{array}{l}\text { Gray, C. L.,Levin, M. E.,du Toit, G.. Patterns of introduction of solids in South African children with atopic dermatitis: } \\
\text { Do they affect allergy rates?. Current Allergy and Clinical Immunology. 2014;27:334-336. }\end{array}$ & $\begin{array}{l}\text { Study design, Health } \\
\text { Status }\end{array}$ \\
\hline 49 & $\begin{array}{l}\text { Greenhawt, M.,Venter, C.. Having your cake and EATing it too: early timing of multiple allergen introduction does } \\
\text { not increase the risk of developing food allergy in standard risk, breastfed infants. Evid Based Med. } 2017 .\end{array}$ & Study design \\
\hline 50 & $\begin{array}{l}\text { Greenhawt, M.. Early Allergen Introduction for Preventing Development of Food Allergy [editorial]. Jama. } \\
\text { 2016;316:1157-1159. }\end{array}$ & Study design \\
\hline 51 & $\begin{array}{l}\text { Greenhawt, M.. Early Allergen Introduction for Preventing Development of Food Allergy. Jama. 2016;316:1157- } \\
\text { 1159. }\end{array}$ & Study design \\
\hline 52 & $\begin{array}{l}\text { Guilbert, T. W.,Stern, D. A.,Morgan, W. J.,Martinez, F. D.,Wright, A. L.. Effect of breastfeeding on lung function in } \\
\text { childhood and modulation by maternal asthma and atopy. Am J Respir Crit Care Med. 2007;176:843-8. }\end{array}$ & Independent Variable \\
\hline 53 & $\begin{array}{l}\text { Gupta, R. S.,Walkner, M. M.,Greenhawt, M.,Lau, C. H.,Caruso, D.,Wang, X.,Pongracic, J. A.,Smith, B.. Food } \\
\text { Allergy Sensitization and Presentation in Siblings of Food Allergic Children. Journal of Allergy and Clinical } \\
\text { Immunology: In Practice. 2016;4:956-962. }\end{array}$ & $\begin{array}{l}\text { Health Status, } \\
\text { Independent Variable }\end{array}$ \\
\hline 54 & $\begin{array}{l}\text { Halken, S.,Host, A.,Hansen, L. G.,Osterballe, O.. Effect of an allergy prevention programme on incidence of atopic } \\
\text { symptoms in infancy. A prospective study of } 159 \text { "high-risk" infants. Allergy. 1992;47:545-53. }\end{array}$ & Independent Variable \\
\hline 55 & Halken, S.. What causes allergy and asthma? The role of dietary factors. Pediatr Pulmonol Suppl. 2004;26:223-4. & Study design \\
\hline
\end{tabular}




\begin{tabular}{|c|c|c|}
\hline & Citation & Reasons for Exclusion \\
\hline 56 & $\begin{array}{l}\text { Hartman, H.,Dodd, C.,Rao, M.,DeBlasio, D.,Labowsky, C.,D'Souza, S.,Lenkauskas, S., Roeser, E.,Heffernan, } \\
\text { A.,Assa'ad, A.. Parental timing of allergenic food introduction in urban and suburban populations. Ann Allergy } \\
\text { Asthma Immunol. 2016;117. }\end{array}$ & Dependent Variable \\
\hline 57 & Hill, D. J.,Hosking, C. S.. Preventing childhood allergy. Med J Aust. 1993;158:367-9. & Study design \\
\hline 58 & Holmes, S.. Planning for the best start in life. A guide to infant feeding. Prof Nurse. 1991;6:200-5. & Study design \\
\hline 59 & $\begin{array}{l}\text { Hon, K. L. E.,Tsang, Y. C.,Poon, T. C. W.,Pong, N. H. H.,Luk, N. M.,Leung, T. N. H.,Chow, C. M.,Leung, T. F.. } \\
\text { Dairy and nondairy beverage consumption for childhood atopic eczema: What health advice to give?. Clinical and } \\
\text { Experimental Dermatology. 2016;41:129-137. }\end{array}$ & Study design, Age \\
\hline 60 & $\begin{array}{l}\text { Horwitz, A. A.,Hossain, J.,Yousef, E.. Correlates of outcome for atopic dermatitis. Ann Allergy Asthma Immunol. } \\
\text { 2009;103:146-51. }\end{array}$ & $\begin{array}{l}\text { Study design, Health } \\
\text { Status }\end{array}$ \\
\hline 61 & $\begin{array}{l}\text { Howie, P. W.,Forsyth, J. S.,Ogston, S. A.,Clark, A.,Florey, C. D.. Protective effect of breast feeding against } \\
\text { infection. Bmj. 1990;300:11-6. }\end{array}$ & Independent Variable \\
\hline 62 & $\begin{array}{l}\text { Hua, M. C., Chen, C. C.,Liao, S. L.,Yao, T. C.,Tsai, M. H.,Lai, S. H.,Chiu, C. Y.,Yeh, K. W.,Huang, J. L.. Faecal } \\
\text { eosinophil cationic protein and serum immunoglobulin E in relation to infant feeding practices. Ann Clin Biochem. } \\
2016 .\end{array}$ & Dependent Variable \\
\hline 63 & $\begin{array}{l}\text { Ito, J.,Fujiwara, T.. Breastfeeding and risk of atopic dermatitis up to the age } 42 \text { months: a birth cohort study in } \\
\text { Japan. Ann Epidemiol. 2014;24:267-72. }\end{array}$ & Independent Variable \\
\hline 64 & Juto, P.,Bjorksten, B.. Serum IgE in infants and influence of type of feeding. Clin Allergy. 1980;10:593-600. & Independent Variable \\
\hline 65 & $\begin{array}{l}\text { Juto, P.,Moller, C.,Engberg, S.,Bjorksten, B.. Influence of type of feeding on lymphocyte function and development } \\
\text { of infantile allergy. Clin Allergy. 1982;12:409-16. }\end{array}$ & Independent Variable \\
\hline 66 & $\begin{array}{l}\text { Kajosaari, M.. Atopy prophylaxis in high-risk infants. Prospective 5-year follow-up study of children with six months } \\
\text { exclusive breastfeeding and solid food elimination (not peer review). Adv Exp Med Biol. 1991;310:453-8. }\end{array}$ & Study design \\
\hline 67 & Kaufman, H. S.,Frick, O. L.. Prevention of asthma. Clin Allergy. 1981;11:549-53. & Independent Variable \\
\hline 68 & $\begin{array}{l}\text { Khoo, P.,Boyce, S.. Does early introduction of allergenic foods decrease the risk of food allergies?. J Paediatr } \\
\text { Child Health. 2016;52:850. }\end{array}$ & Study design \\
\hline 69 & $\begin{array}{l}\text { Kiefte-de Jong, J. C.,de Vries, J. H.,Franco, O. H.,Jaddoe, V. W.,Hofman, A., Raat, H.,de Jongste, J. C.,Moll, H. A.. } \\
\text { Fish consumption in infancy and asthma-like symptoms at preschool age. Pediatrics. 2012;130:1060-8. }\end{array}$ & Dependent Variable \\
\hline 70 & $\begin{array}{l}\text { Kiefte-de Jong, J. C.,Escher, J. C.,Arends, L. R., Jaddoe, V. W.,Hofman, A., Raat, H.,Moll, H. A.. Infant nutritional } \\
\text { factors and functional constipation in childhood: the Generation R study. Am J Gastroenterol. 2010;105:940-5. }\end{array}$ & Dependent Variable \\
\hline
\end{tabular}




\begin{tabular}{|c|c|c|}
\hline & Citation & Reasons for Exclusion \\
\hline 71 & $\begin{array}{l}\text { Kim, J.,Chung, Y.,Han, Y.,Ahn, K., Lee, S. I.. The natural history and prognostic factors of egg allergy in Korean } \\
\text { infants with atopic dermatitis. Asian Pac J Allergy Immunol. 2009;27:107-14. }\end{array}$ & Health Status \\
\hline 72 & $\begin{array}{l}\text { Kmietowicz, Zosia. Risk of peanut allergy can be reduced by } 80 \% \text { by including peanuts in infant diets. BMJ: British } \\
\text { Medical Journal. } 2015 ; 350 \text {. }\end{array}$ & Study design \\
\hline 73 & Koletzko, B.. Complementary foods and the development of food allergy. Pediatrics. 2000;106:1285. & Study design \\
\hline 74 & Koletzko, S.. 2.5 Allergy Prevention through Early Nutrition. World Rev Nutr Diet. 2015;113:113-7. & Study design \\
\hline 75 & $\begin{array}{l}\text { Koplin, J. J.,Osborne, N. J.,Wake, M.,Martin, P. E.,Gurrin, L. C.,Robinson, M. N.,Tey, D.,Slaa, M.,Thiele, L.,Miles, } \\
\text { L.,Anderson, D.,Tan, T.,Dang, T. D.,Hill, D. J.,Lowe, A. J.,Matheson, M. C.,Ponsonby, A. L.,Tang, M. L.,Dharmage, } \\
\text { S. C.,Allen, K. J.. Can early introduction of egg prevent egg allergy in infants? A population-based study. J Allergy } \\
\text { Clin Immunol. 2010;126:807-13. }\end{array}$ & $\begin{array}{l}\text { Study design, Independent } \\
\text { Variable }\end{array}$ \\
\hline 76 & $\begin{array}{l}\text { Koplin, J.,Dharmage, S. C.,Gurrin, L.,Osborne, N.,Tang, M. L.,Lowe, A. J.,Hosking, C.,Hill, D.,Allen, K. J.. Soy } \\
\text { consumption is not a risk factor for peanut sensitization. J Allergy Clin Immunol. 2008;121:1455-9. }\end{array}$ & $\begin{array}{l}\text { Study design, Independent } \\
\text { Variable }\end{array}$ \\
\hline 77 & $\begin{array}{l}\text { Kramer, B.,Raczynska, J.,Kaczmarek, J.,Lukamowicz, J.,Pasowska, R.,Puchala, B.. Genetic and environmental } \\
\text { conditions involved in assessment of the immunological state in children with atopic dermatitis. Rocz Akad Med } \\
\text { Bialymst. 1995;40:439-47. }\end{array}$ & $\begin{array}{l}\text { Study design, Independent } \\
\text { Variable }\end{array}$ \\
\hline 78 & $\begin{array}{l}\text { Kramer, M. S.,Chalmers, B.,Hodnett, E. D.,Sevkovskaya, Z.,Dzikovich, I.,Shapiro, S.,Collet, J. P.,Vanilovich, } \\
\text { I.,Mezen, I.,Ducruet, T.,Shishko, G.,Zubovich, V.,Mknuik, D.,Gluchanina, E.,Dombrovskiy, V.,Ustinovitch, A.,Kot, } \\
\text { T.,Bogdanovich, N.,Ovchinikova, L.,Helsing, E.. Promotion of Breastfeeding Intervention Trial (PROBIT): a } \\
\text { randomized trial in the Republic of Belarus. Jama. 2001;285:413-20. }\end{array}$ & Independent Variable \\
\hline 79 & $\begin{array}{l}\text { Kramer, M. S.,Moroz, B.. Do breast-feeding and delayed introduction of solid foods protect against subsequent } \\
\text { atopic eczema?. J Pediatr. 1981;98:546-50. }\end{array}$ & Independent Variable \\
\hline 80 & $\begin{array}{l}\text { Krogulska, A.,Wasowska-Królikowska, K.,Dynowski, J.. Usefulness of atopy patch tests with food allergens in } \\
\text { diagnosis of food allergy in children with dermatitis atopica. Przeglad Pediatryczny. 2007;37:245-249. }\end{array}$ & $\begin{array}{l}\text { Health Status, } \\
\text { Independent Variable, } \\
\text { Language }\end{array}$ \\
\hline 81 & $\begin{array}{l}\text { Kucukosmanoglu, E.,Yazi, D.,Yesil, O.,Akkoc, T.,Gezer, M.,Bakirci, N.,Bahceciler, N. N.,Barlan, I. B.. Prevalence of } \\
\text { egg sensitization in Turkish infants based on skin prick test. Allergol Immunopathol (Madr). 2008;36:141-4. }\end{array}$ & Study design \\
\hline 82 & $\begin{array}{l}\text { Kummeling, I.,Thijs, C.,Huber, M.,van de Vijver, L. P.,Snijders, B. E.,Penders, J.,Stelma, F.,van Ree, R.,van den } \\
\text { Brandt, P. A.,Dagnelie, P. C.. Consumption of organic foods and risk of atopic disease during the first } 2 \text { years of life } \\
\text { in the Netherlands. Br J Nutr. 2008;99:598-605. }\end{array}$ & Study design \\
\hline 83 & $\begin{array}{l}\text { Laubereau, B.,Brockow, I.,Zirngibl, A.,Koletzko, S.,Gruebl, A.,von Berg, A.,Filipiak-Pittroff, B.,Berdel, D.,Bauer, C. } \\
\text { P.,Reinhardt, D.,Heinrich, J.,Wichmann, H. E.. Effect of breast-feeding on the development of atopic dermatitis } \\
\text { during the first } 3 \text { years of life--results from the GINI-birth cohort study. J Pediatr. 2004;144:602-7. }\end{array}$ & Independent Variable \\
\hline
\end{tabular}




\begin{tabular}{|c|c|c|}
\hline & Citation & Reasons for Exclusion \\
\hline 84 & $\begin{array}{l}\text { Lee, J. M.,Neher, J. O.,Kelsberg, G.,Safranek, S.. Atopic Eczema and Early Introduction of Solid Foods. Am Fam } \\
\text { Physician. 2015;92:523-4. }\end{array}$ & Study design \\
\hline 85 & $\begin{array}{l}\text { Levin, M.,Goga, A., Doherty, T.,Coovadia, H.,Sanders, D.,Green, R. J.,Kling, S.. Allergy and infant feeding } \\
\text { guidelines in the context of resource-constrained settings. J Allergy Clin Immunol. } 2016 .\end{array}$ & Study design \\
\hline 86 & $\begin{array}{l}\text { Luoma, R.. Environmental allergens and morbidity in atopic and non-atopic families. Acta Paediatr Scand. } \\
\text { 1984;73:448-53. }\end{array}$ & Independent Variable \\
\hline 87 & $\begin{array}{l}\text { Majeed, R.,Rajar, U. D.,Shaikh, N.,Majeed, F.,Arain, A. A.. Risk factors associated with childhood asthma. J Coll } \\
\text { Physicians Surg Pak. 2008;18:299-302. }\end{array}$ & Independent Variable \\
\hline 88 & $\begin{array}{l}\text { Mauro-Martín, I. S.,Bodega-Villanueva, P.,Romero-Caamaño, E.,Micó-Moreno, V.,Garicano-Vilar, E.. Association } \\
\text { between timing of food introduction in on first year old and the prevalence of allergies [spanish]. Revista Espanola } \\
\text { de Nutricion Humana y Dietetica. 2014;18:145-154. }\end{array}$ & Language \\
\hline 89 & $\begin{array}{l}\text { Mavale-Manuel, S.,Alexandre, F.,Duarte, N.,Albuquerque, O.,Scheinmann, P.,Poisson-Salomon, A. S., de Blic, J.. } \\
\text { Risk factors for asthma among children in Maputo (Mozambique). Allergy. 2004;59:388-93. }\end{array}$ & Independent Variable \\
\hline 90 & $\begin{array}{l}\text { McKean, M.,Caughey, A. B.,Leong, R. E.,Wong, A.,Cabana, M. D.. The Timing of Infant Food Introduction in } \\
\text { Families With a History of Atopy. Clin Pediatr (Phila). 2015;54:745-51. }\end{array}$ & Dependent Variable \\
\hline 91 & $\begin{array}{l}\text { Metcalfe, J. R.,D'Vaz, N.,Makrides, M.,Gold, M. S.,Quinn, P.,West, C. E.,Loh, R.,Prescott, S. L.,Palmer, D. J.. } \\
\text { Elevated IL-5 and IL-13 responses to egg proteins predate the introduction of egg in solid foods in infants with } \\
\text { eczema. Clin Exp Allergy. 2016;46:308-16. }\end{array}$ & $\begin{array}{l}\text { Health Status, Dependent } \\
\text { Variable }\end{array}$ \\
\hline 92 & Midwinter, R. E.,Morris, A. F.,Colley, J. R.. Infant feeding and atopy. Arch Dis Child. 1987;62:965-7. & $\begin{array}{l}\text { Study design, Independent } \\
\text { Variable }\end{array}$ \\
\hline 93 & $\begin{array}{l}\text { Mihrshahi, S.,Webb, K.,Almqvist, C.,Kemp, A. S.. Adherence to allergy prevention recommendations in children } \\
\text { with a family history of asthma. Pediatr Allergy Immunol. 2008;19:355-62. }\end{array}$ & Dependent Variable \\
\hline 94 & $\begin{array}{l}\text { Milner, J. D.,Stein, D. M.,McCarter, R.,Moon, R. Y.. Early infant multivitamin supplementation is associated with } \\
\text { increased risk for food allergy and asthma. Pediatrics. 2004;114:27-32. }\end{array}$ & Independent Variable \\
\hline 95 & $\begin{array}{l}\text { Miyake, Y.,Yura, A.,Iki, M.. Breastfeeding and the prevalence of symptoms of allergic disorders in Japanese } \\
\text { adolescents. Clin Exp Allergy. 2003;33:312-6. }\end{array}$ & Study design \\
\hline 96 & $\begin{array}{l}\text { Moore, W. J.,Midwinter, R. E.,Morris, A. F.,Colley, J. R.,Soothill, J. F.. Infant feeding and subsequent risk of atopic } \\
\text { eczema. Arch Dis Child. 1985;60:722-6. }\end{array}$ & Independent Variable \\
\hline 97 & $\begin{array}{l}\text { Morgan, J. B.,Lucas, A.,Fewtrell, M. S.. Does weaning influence growth and health up to } 18 \text { months?. Archives of } \\
\text { Disease in Childhood: Education and Practice Edition. 2004;89:728-733. }\end{array}$ & Study design \\
\hline
\end{tabular}




\begin{tabular}{|c|c|c|}
\hline & Citation & Reasons for Exclusion \\
\hline 98 & Morin, K. H.. Food Allergies: New Evidence for Peanut Introduction. MCN Am J Matern Child Nurs. 2016;41:188. & Study design \\
\hline 99 & $\begin{array}{l}\text { Nakamura, Y.,Oki, I.,Tanihara, S.,Ojima, T.,Ito, Y.,Yamazaki, O.,Iwama, M.,Tabata, Y.,Katsuyama, K.,Sasai, } \\
\text { Y.,Nakagawa, M.,Matsushita, A.,Hossaka, K.,Sato, J.,Hidaka, Y.,Uda, H.,Nakamata, K.,Yanagawa, H.. Relationship } \\
\text { between breast milk feeding and atopic dermatitis in children. J Epidemiol. 2000;10:74-8. }\end{array}$ & $\begin{array}{l}\text { Study design, Independent } \\
\text { Variable }\end{array}$ \\
\hline 100 & & Language \\
\hline 101 & $\begin{array}{l}\text { Natsume, O.,Kabashima, S.,Nakasato, J.,Yamamoto-Hanada, K.,Narita, M.,Kondo, M.. Early introduction of egg for } \\
\text { infants with atopic dermatitis to prevent egg allergy: A double-blind placebo-controlled randomized clinical } \\
\text { trial[abstract only]. Journal of Allergy and Clinical Immunology. } 2016 ; 137 .\end{array}$ & Study design \\
\hline 102 & Neild, V.. Diet and atopic eczema. Mod Midwife. 1994;4:22. & Study design \\
\hline 103 & $\begin{array}{l}\text { Nwaru, B. I.,Erkkola, M.,Ahonen, S.,Kaila, M.,Haapala, A. M.,Kronberg-Kippila, C.,Salmelin, R.,Veijola, R.,Ilonen, } \\
\text { J.,Simell, O.,Knip, M.,Virtanen, S. M.. Age at the introduction of solid foods during the first year and allergic } \\
\text { sensitization at age } 5 \text { years. Pediatrics. 2010;125:50-9. }\end{array}$ & Dependent Variable \\
\hline 104 & $\begin{array}{l}\text { Nwaru, B. I.,Takkinen, H. M.,Niemela, O.,Kaila, M.,Erkkola, M.,Ahonen, S.,Tuomi, H.,Haapala, A. M.,Kenward, M. } \\
\text { G.,Pekkanen, J.,Lahesmaa, R.,Kere, J.,Simell, O.,Veijola, R.,llonen, J.,Hyoty, H.,Knip, M.,Virtanen, S. M.. } \\
\text { Introduction of complementary foods in infancy and atopic sensitization at the age of } 5 \text { years: timing and food } \\
\text { diversity in a Finnish birth cohort. Allergy. } 2013 ; 68: 507-16 .\end{array}$ & Dependent Variable \\
\hline 105 & $\begin{array}{l}\text { Oddy, W. H.,Sherriff, J. L.. Breastfeeding, body mass index, asthma and atopy in children. Asia Pac J Public } \\
\text { Health. } 2003 .\end{array}$ & Independent Variable \\
\hline 106 & $\begin{array}{l}\text { Oddy, W. H.. Breastfeeding and asthma in children: findings from a West Australian study. Breastfeed Rev. } \\
\text { 2000;8:5-11. }\end{array}$ & Independent Variable \\
\hline 107 & Oehling, A.. Importance of food allergy in childhood asthma. Allergol Immunopathol (Madr). 1981:71-3. & Study design \\
\hline 108 & $\begin{array}{l}\text { Ogbuanu, I. U.,Karmaus, W.,Arshad, S. H.,Kurukulaaratchy, R. J.,Ewart, S.. Effect of breastfeeding duration on } \\
\text { lung function at age } 10 \text { years: a prospective birth cohort study. Thorax. 2009;64:62-6. }\end{array}$ & Independent Variable \\
\hline 109 & $\begin{array}{l}\text { Ozmert, E. N.,Kale-Cekinmez, E.,Yurdakok, K.,Sekerel, B. E.. Determinants of allergic signs and symptoms in 24- } \\
\text { 48-month-old Turkish children. Turk J Pediatr. 2009;51:103-9. }\end{array}$ & Study design \\
\hline 110 & $\begin{array}{l}\text { Parihar, H.,Kumar, L.,Puri, R.,Kumar, V.. The incidence of allergic diseases and feeding patterns in children upto } 2 \\
\text { years of age. Indian J Pediatr. 1984;51:7-12. }\end{array}$ & Study design \\
\hline 111 & $\begin{array}{l}\text { Paton, J.,Kljakovic, M.,Ciszek, K.,Ding, P.. Infant Feeding Practices and Nut Allergy over Time in Australian School } \\
\text { Entrant Children. Int J Pediatr. 2012;2012:675724. }\end{array}$ & Study design, Age \\
\hline
\end{tabular}




\begin{tabular}{|c|c|c|}
\hline & Citation & Reasons for Exclusion \\
\hline 112 & $\begin{array}{l}\text { Pesonen, M.,Kallio, M. J.,Ranki, A.,Siimes, M. A.. Prolonged exclusive breastfeeding is associated with increased } \\
\text { atopic dermatitis: a prospective follow-up study of unselected healthy newborns from birth to age } 20 \text { years. Clin } \\
\text { Exp Allergy. 2006;36:1011-8. }\end{array}$ & Independent Variable \\
\hline 113 & $\begin{array}{l}\text { Peters, R. L.,Allen, K. J.,Dharmage, S. C.,Lodge, C. J.,Koplin, J. J.,Ponsonby, A. L.,Wake, M.,Lowe, A. J.,Tang, M. } \\
\text { L.,Matheson, M. C.,Gurrin, L. C.. Differential factors associated with challenge-proven food allergy phenotypes in a } \\
\text { population cohort of infants: a latent class analysis. Clin Exp Allergy. 2015;45:953-63. }\end{array}$ & Study design \\
\hline 114 & $\begin{array}{l}\text { Peters, T. J.,Golding, J.. The epidemiology of childhood eczema: II. Statistical analyses to identify independent } \\
\text { early predictors. Paediatr Perinat Epidemiol. 1987;1:80-94. }\end{array}$ & Independent Variable \\
\hline 115 & $\begin{array}{l}\text { Pitt, Tj,Watson, W.,Ferguson, A.,Dimich-Ward, H.,Dybuncio, A.,Kozyrskyj, Al. Delay In The Introduction Of } \\
\text { Allergenic Foods Is Not Associated With An Increased Risk For Sensitization In A High Risk Cohort [Abstract]. } \\
\text { Journal of allergy and clinical immunology. 2010;125. }\end{array}$ & Study design \\
\hline 116 & Pohl, C. A.. Timing of cereal introduction to the infant diet. Patient Care for the Nurse Practitioner. 2006;9. & Study design \\
\hline 117 & $\begin{array}{l}\text { Pohlabeln, H.. Effect modification by familial predisposition when analyzing the influence of breastfeeding and pet } \\
\text { keeping on the development of allergic diseases in children [german]. Allergologie. 2012;35:44-53. }\end{array}$ & Language \\
\hline 118 & $\begin{array}{l}\text { Poongadan, M. N.,Gupta, N.,Kumar, R.. Dietary pattern and asthma in India. Pneumonol Alergol Pol. 2016;84:160- } \\
\text { 7. }\end{array}$ & Age \\
\hline 119 & $\begin{array}{l}\text { Poysa, L.,Pulkkinen, A.,Korppi, M.,Remes, K.,Juntunen-Backman, K.. Diet in infancy and bronchial hyperreactivity } \\
\text { later in childhood. Pediatr Pulmonol. 1992;13:215-21. }\end{array}$ & Independent Variable \\
\hline 120 & $\begin{array}{l}\text { Poysa, L.. Atopy in children with and without a family history of atopy. II. Skin reactivity. Acta Paediatr Scand. } \\
\text { 1989;78:902-6. }\end{array}$ & Independent Variable \\
\hline 121 & $\begin{array}{l}\text { Prasad, S., Rana, R. K.,Sheth, R.,Mauskar, A. V.. A Hospital Based Study to Establish the Correlation between } \\
\text { Recurrent Wheeze and Vitamin D Deficiency Among Children of Age Group Less than } 3 \text { Years in Indian Scenario. } \\
\text { J Clin Diagn Res. 2016;10. }\end{array}$ & $\begin{array}{l}\text { Independent Variable, } \\
\text { Dependent Variable }\end{array}$ \\
\hline 122 & Pratt, H. F.. Breastfeeding and eczema. Early Hum Dev. 1984;9:283-90. & Independent Variable \\
\hline 123 & Pugh, R. J.. Infant feeding in perspective. Practitioner. 1982;226:1917-25. & Study design \\
\hline 124 & $\begin{array}{l}\text { Quah, P. L.,Loo, E. X.,Lee, G. N.,Kuo, I. C.,Gerez, I.,Llanora, G. V.,Chan, Y. H.,Aw, M.,Shek, L. P.,Lee, B. W.. } \\
\text { Clinical phenotype and allergen sensitization in the first } 2 \text { years as predictors of atopic disorders at age } 5 \text { years. } \\
\text { World Allergy Organ J. 2015;8:33. }\end{array}$ & Independent Variable \\
\hline 125 & Rosenberg, K.. Early Introduction Reduces Risk of Some Food Allergies. Am J Nurs. 2017;117:65-66. & Study design \\
\hline
\end{tabular}




\begin{tabular}{|c|c|c|}
\hline & Citation & Reasons for Exclusion \\
\hline 126 & $\begin{array}{l}\text { Roslan, K.,Szczepanski, M.,Kaczmarski, M.,Zapolska, B.,Uscinowicz, M.,Wasilewska, J.,Solarz, E.. Environmental } \\
\text { and constitutional conditions and food hypersensitivity in children. Rocz Akad Med Bialymst. 1995;40:448-51. }\end{array}$ & $\begin{array}{l}\text { Study design, Health } \\
\text { Status }\end{array}$ \\
\hline 127 & $\begin{array}{l}\text { Satwani, H.,Rehman, A.,Ashraf, S.,Hassan, A.. Is serum total IgE levels a good predictor of allergies in children?. J } \\
\text { Pak Med Assoc. 2009;59:698-702. }\end{array}$ & Study design \\
\hline 128 & $\begin{array}{l}\text { Sausenthaler, S.,Heinrich, J.,Koletzko, S.. Early diet and the risk of allergy: What can we learn from the prospective } \\
\text { birth cohort studies GINIplus and LISAplus?. American Journal of Clinical Nutrition. } 2011 ; 94 .\end{array}$ & Study design \\
\hline 129 & $\begin{array}{l}\text { Sherriff, A.,Peters, T. J.,Henderson, J.,Strachan, D.. Risk factor associations with wheezing patterns in children } \\
\text { followed longitudinally from birth to 3(1/2) years. Int J Epidemiol. 2001;30:1473-84. }\end{array}$ & Independent Variable \\
\hline 130 & $\begin{array}{l}\text { Shohet, L.,Shahar, E.,Davidson, S.. Breast feeding as prophylaxis for atopic eczema: a controlled study of } 368 \\
\text { cases. Acta Paediatr Hung. 1985;26:35-9. }\end{array}$ & Independent Variable \\
\hline 131 & $\begin{array}{l}\text { Siltanen, M.,Kajosaari, M.,Poussa, T.,Saarinen, K. M.,Savilahti, E.. A dual long-term effect of breastfeeding on } \\
\text { atopy in relation to heredity in children at } 4 \text { years of age. Allergy. 2003;58:524-30. }\end{array}$ & Independent Variable \\
\hline 132 & $\begin{array}{l}\text { Silvers, K. M.,Frampton, C. M.,Wickens, K.,Pattemore, P. K.,Ingham, T.,Fishwick, D.,Crane, J.,Town, G. I.,Epton, } \\
\text { M. J.. Breastfeeding protects against current asthma up to } 6 \text { years of age. J Pediatr. 2012;160. }\end{array}$ & Independent Variable \\
\hline 133 & Smith, P.. Dietary prevention of food allergies in infants. Australian Journal of Pharmacy. 2012;93:80-83. & Study design \\
\hline 134 & $\begin{array}{l}\text { Sybilski, A. J.,Doboszyńska, A.,Samoliński, B.. Influence of selected risk factors on the development of allergy } \\
\text { during the first year of life [polish]. Przeglad Pediatryczny. 2008;38:13-19. }\end{array}$ & $\begin{array}{l}\text { Independent Variable, } \\
\text { Language }\end{array}$ \\
\hline 135 & Ta, V.,Laubach, S.. Introduction of complementary foods and the relationship to food allergy. Pediatrics. 2014. & Study design \\
\hline 136 & Taitz, L.. Feeding children in the first year of life. Community Nurse. 1990;26:81-84. & Study design \\
\hline 137 & $\begin{array}{l}\text { Takemura, Y.,Sakurai, Y.,Honjo, S.,Kusakari, A.,Hara, T.,Gibo, M.,Tokimatsu, A.,Kugai, N.. Relation between } \\
\text { breastfeeding and the prevalence of asthma : the Tokorozawa Childhood Asthma and Pollinosis Study. Am J } \\
\text { Epidemiol. 2001;154:115-9. }\end{array}$ & Independent Variable \\
\hline 138 & $\begin{array}{l}\text { Tan, Jw- L.,Valerio, C.,Barnes, E. H.,Asperen, P. P.,Kakakios, A. M.,Campbell, D. E.. Early introduction of dietary } \\
\text { egg reduces egg sensitization at } 12 \text { months of age in infants at risk of allergic disease [abstract only]. Journal of } \\
\text { Allergy and Clinical Immunology. } 2016 ; 137 .\end{array}$ & Study design \\
\hline 139 & Taylor, B.. Infant feeding and allergy: fact and fiction. Midwife Health Visit Community Nurse. 1984;20:354-60. & Study design \\
\hline 140 & $\begin{array}{l}\text { Tromp,, II,Briede, S.,Kiefte-de Jong, J. C., Renders, C. M.,Jaddoe, V. W.,Franco, O. H.,Hofman, A.,Raat, H.,Moll, H. } \\
\text { A.. Factors associated with the timing of introduction of complementary feeding: the Generation R Study. Eur J Clin } \\
\text { Nutr. 2013;67:625-30. }\end{array}$ & Dependent Variable \\
\hline
\end{tabular}




\begin{tabular}{|c|c|c|}
\hline & Citation & Reasons for Exclusion \\
\hline 141 & $\begin{array}{l}\text { van Odijk, J.,Hulthen, L.,Ahlstedt, S.,Borres, M. P.. Introduction of food during the infant's first year: a study with } \\
\text { emphasis on introduction of gluten and of egg, fish and peanut in allergy-risk families. Acta Paediatr. 2004;93:464- } \\
70 \text {. }\end{array}$ & $\begin{array}{l}\text { Study design, Dependent } \\
\text { Variable }\end{array}$ \\
\hline 142 & $\begin{array}{l}\text { Ventura, A.,De Seta, L.,Martelossi, S.,Florean, P.,Maggiore, G.,Salvatore, C. M.,Berzioli, M.,Guidobaldi, } \\
\text { G.,Lorenzini, G.,Peressini, P.,Pesenti, P.,Rollo, G.,Sacher, B.,Santoro, L.,Stanzione, V.,Stranamore, D.,Zannerio, } \\
\text { E.. Soy allergy and DSCG in atopic eczema: "much ado about nothing"?. Pediatr Med Chir. 1996;18:283-8. }\end{array}$ & $\begin{array}{l}\text { Health Status, } \\
\text { Independent Variable }\end{array}$ \\
\hline 143 & $\begin{array}{l}\text { Verduci, E.,Banderali, G.,Peroni, D.,Lassandro, C.,Radaelli, G.. Duration of exclusive breastfeeding and wheezing } \\
\text { in the first year of life: A longitudinal study. Allergol Immunopathol (Madr). } 2016 .\end{array}$ & Independent Variable \\
\hline 144 & Visser, H. K.. Dietary influences on infection and allergy in infants: introduction. J Nutr. 2008;138. & Study design \\
\hline 145 & Waddell, L.. Introduction of solids in babies at risk of allergies. J Fam Health Care. 2014;24:22-7. & Study design \\
\hline 146 & $\begin{array}{l}\text { Waidyatillake, N. T.,Simpson, J. A.,Allen, K. J.,Lodge, C. J.,Dharmage, S. C.,Abramson, M. J.,De Livera, A. } \\
\text { M.,Matheson, M. C.,Erbas, B.,Hill, D. J.,Lowe, A. J.. The effect of breastfeeding on lung function at } 12 \text { and } 18 \\
\text { years: A prospective cohort study. European Respiratory Journal. 2016;48:125-132. }\end{array}$ & Independent Variable \\
\hline 147 & $\begin{array}{l}\text { Wegienka, G.,Ownby, D. R.,Havstad, S.,Williams, L. K.,Johnson, C. C.. Breastfeeding history and childhood allergic } \\
\text { status in a prospective birth cohort. Ann Allergy Asthma Immunol. 2006;97:78-83. }\end{array}$ & Independent Variable \\
\hline 148 & $\begin{array}{l}\text { West, C. E.,Hammarstrom, M. L.,Hernell, O.. Probiotics during weaning reduce the incidence of eczema. Pediatr } \\
\text { Allergy Immunol. 2009;20:430-7. }\end{array}$ & Independent Variable \\
\hline 149 & $\begin{array}{l}\text { White, J. M.,McFadden, J. P.. Contact allergens in food ingredients and additives: atopy and the hapten-atopy } \\
\text { hypothesis. Contact Dermatitis. 2008;58:245-6. }\end{array}$ & $\begin{array}{l}\text { Study design, Dependent } \\
\text { Variable }\end{array}$ \\
\hline 150 & $\begin{array}{l}\text { Woicka-Kolejwa, K.,Zaczeniuk, M.,Majak, P.,Pawlowska-Iwanicka, K.,Kopka, M.,Stelmach, W.,Jerzynska, } \\
\text { J.,Stelmach, I.. Food allergy is associated with recurrent respiratory tract infections during childhood. Postepy } \\
\text { Dermatol Alergol. 2016;33:109-13. }\end{array}$ & $\begin{array}{l}\text { Study design, Dependent } \\
\text { Variable }\end{array}$ \\
\hline 151 & $\begin{array}{l}\text { Woś, H.,Cholewa, Z.,Brozek, G.. The influence of breast-feeding on the rate of occurrence of bronchial asthma in } \\
\text { children at the younger school age. Pediatria Wspolczesna. } 2003 ; 5: 21-27 \text {. }\end{array}$ & $\begin{array}{l}\text { Independent Variable, } \\
\text { Language }\end{array}$ \\
\hline 152 & $\begin{array}{l}\text { Wright, A. L.,Holberg, C. J.,Martinez, F. D.,Halonen, M.,Morgan, W.,Taussig, L. M.. Epidemiology of physician- } \\
\text { diagnosed allergic rhinitis in childhood. Pediatrics. 1994;94:895-901. }\end{array}$ & Dependent Variable \\
\hline 153 & $\begin{array}{l}\text { Wright, A. L.,Holberg, C. J.,Taussig, L. M.,Martinez, F. D.. Factors influencing the relation of infant feeding to } \\
\text { asthma and recurrent wheeze in childhood. Thorax. 2001;56:192-7. }\end{array}$ & Independent Variable \\
\hline 154 & $\begin{array}{l}\text { Wright, A. L.,Holberg, C. J.,Taussig, L. M.,Martinez, F.. Maternal asthma status alters relation of infant feeding to } \\
\text { asthma in childhood [not peer rev jl). Adv Exp Med Biol. 2000;478:131-7. }\end{array}$ & Study design \\
\hline
\end{tabular}




\begin{tabular}{|l|l|l|}
\hline & Citation & Reasons for Exclusion \\
\hline 155 & $\begin{array}{l}\text { Xu, M.,Wang, Y.,Dai, Z.,Zhang, Y.,Li, Y.,Wang, J.. Comparison of growth and nutritional status in infants receiving } \\
\text { goat milk-based formula and cow milk-based formula: A randomized, double-blind study. Food and Nutrition } \\
\text { Research. 2015;59. }\end{array}$ & $\begin{array}{l}\text { Independent Variable, } \\
\text { Dependent Variable }\end{array}$ \\
\hline 156 & $\begin{array}{l}\text { Yamakawa, M.,Yorifuji, T.,Kato, T.,Yamauchi, Y.,Doi, H.. Breast-feeding and hospitalization for asthma in early } \\
\text { childhood: a nationwide longitudinal survey in Japan. Public Health Nutr. 2015;18:1756-61. }\end{array}$ & Independent Variable \\
\hline 157 & $\begin{array}{l}\text { Young, H. B.,Buckley, A. E.,Hamza, B.,Mandarano, C.. Milk and lactation: some social and developmental } \\
\text { correlates among 1,000 infants. Pediatrics. 1982;69:169-75. }\end{array}$ & $\begin{array}{l}\text { Study design, Independent } \\
\text { Variable }\end{array}$ \\
\hline 158 & $\begin{array}{l}\text { Zeiger, R. S.,Heller, S.,Mellon, M. H.,Forsythe, A. B.,O'Connor, R. D.,Hamburger, R. N.,Schatz, M.. Effect of } \\
\text { combined maternal and infant food-allergen avoidance on development of atopy in early infancy: a randomized } \\
\text { study. J Allergy Clin Immunol. 1989;84:72-89. }\end{array}$ & Independent Variable \\
\hline
\end{tabular}

